\title{
Comparative Study of Calculation Models for the Fire Resistance of Hollow Steel Columns Filled with Concrete
}

\author{
Farid Fellah" ${ }^{*}$ \\ ${ }^{1}$ Civil Engineering Laboratory LGC, Faculty of Engineering Sciences, Badji Mokhtar University, 23000 Annaba, P.O.B. 12, Algeria \\ * Corresponding author, e-mail: farid.fellah@univ-annaba.dz
}

Received: 07 June 2019, Accepted: 21 October 2019, Published online: 27 January 2020

\begin{abstract}
Various calculation methods are proposed in codes for the evaluation of fire resistance of hollow steel columns filled with concrete, but the use of some of them may be very tedious for design engineers, and it may be interesting to have more practical tools at their disposal. In the comparative study presented here, three methods based on different procedures are investigated. Kodur's method is a set of formulas allowing to calculate the fire resistance or the maximum applied load. Potfire is a computer program for which a user's manual is provided and clean instructions describe how to introduce the data. SAFIR is a non-linear computer code that can simulate the behavior of structures under fire conditions. Comparisons are made between the results obtained by the three methods and test results. The differences are analyzed, and the influence of some parameters is examined. From the results obtained in this comparative study, it is possible to say in which cases each method can be used.
\end{abstract}

Keywords

composite steel-concrete construction, columns, hollow steel sections, fire resistance, numerical analysis, non-linearity

\section{Introduction}

Concrete Filled Steel Hollow Section (CFSHS) columns are presently used very often in high-rise buildings where the columns have to carry heavy loads. They are appreciated by engineers because they are very efficient structurally and by architects as they are visually very pleasant compared to other types of columns.

There are many advantages of using CFSHS columns. Due to the infill the columns remain slender and can bear higher loads without increasing the external dimensions. The hollow section acts as formwork as well as reinforcement for the concrete. In CFSHS columns when subjected to axial compression under ambient temperature conditions, lateral deformations occur at the cross-section of the concrete core. This latter tend to extends laterally and the SHS steel tube will prevent this expansion. The concrete core will be laterally confined and reinforced transversely by the presence of the steel tube especially for circular columns. This reinforcement becomes more important when the steel tube thickness increases.

However in fire situation, the confinement of the concrete core weakens progressively with the rise of temperature.
Indeed, the SHS tube steel quickly loses its strength and splits from the concrete core.

There is seldom any problem with respect to the joints due to the highly developed assembly technique in structural engineering today.

Research studies on CFSHS columns commenced in Europe in the early 70's [1]. It was soon understood that the fire resistance of these profiles was considerably higher compared to that of steel tubes alone or reinforced concrete alone. Among the advantages offered by the steel tube, note on the one hand the confinement of the reinforced concrete core and secondly, it delays the ruin of the column following the degradation of the mechanical characteristics of the reinforced concrete exposed to fire. Indeed, the strength of the reinforced concrete columns, especially in the central columns, decreases considerably during the rise of temperature and their ruins can occur even in the post-fire phase [2].

Several research projects related to the behavior under fire conditions were undertaken in the 70's and the 80's [3-5]. In North America such studies started later in the 90 's, and have been mainly conducted in Canada [6-8]. 
Calculation methods and design tools for this type of elements are now included in codes and standards, like for example in Eurocodes for ambient [9] as well as for fire conditions [10-11].

The calculation methods prescribed in the codes are often complicated, and it is preferable for design engineers need to have practical tools for a quick and safe design. For example the classical approach in EC4 [11] is a calculation model given in Annex H, for which the temperature distribution over the cross-section has to be calculated. One of the difficulties of developing such practical methods is due to the large scatter of experimental results. Therefore it is not easy to come to safe and economically efficient models.

The large scatter of experimental results is due to the fact that many parameters differ when performing a fire resistance test: heating conditions, way of applying external loads, eccentricity in case of columns, and differ material properties from one element to another.

In this article, three methods allowing the calculation of the fire resistance or the maximum allowable load for a given fire resistance time are examined. The results obtained are compared and the differences are analyzed.

Kodur has proposed formulas based on test results [6-8] and parametric studies for which specific computer programs have been used [12-13]. POTFIRE is a design method developed by CTICM [14], in which the buckling load at elevated temperatures is calculated numerically. SAFIR is a computer code developed at the University of Liege for the simulation of structures submitted to fire [15]. The results obtained by SAFIR have been compared with experimental results and some calibrations have been made $[16,17]$. In a rather recent research work, it has been proved that it can also be applied to more complex elements (steel tubes surrounding another tube or profile filled with self-compacting concrete) [16, 17].

In this paper, comparisons are made between the results obtained by the three methods and test results. The differences are analyzed, and the influence of some parameters in the models is examined. Eccentric loadings and reinforcement ratio are the two parameters considered in this study, while other parameters, like tube thickness, infill and tube strength, aggregate type, etc., might also have a significant influence.

\section{Methods used for the comparative study}

Three methods: Kodur's formulas, POTFIRE and SAFIR are used for the comparison of Concrete Filled Steel Hollow Section (CFSHS) columns with or without rebars. The three methods have been chosen on the following bases. Current North American procedures are based on Kodur's formulas. In Europe POTFIRE has been proposed in order to avoid the complicated method of EC4 [11]. SAFIR has been developed at the University of Liege, and is used world-wide in many universities and research centers. The ASTM E119-88 standard temperature-time curve [18] has been applied to establish Kodur's formulas, while for POTFIRE and SAFIR the ISO 834 [19] has been used. The two curves are very similar, so that the results obtained by these two temperature-time curves can be considered as comparable. As explained hereafter the three methods are based on quite different procedures, and therefore the comparison between the various results will be informative.

\subsection{Kodur's formulas}

Guidelines for the simplified design of CFSHS columns have been elaborated by the National Fire Laboratory and the National Research Council of Canada. They are based on a large experimental program completed by numerical simulations.

Fifty-eight CFSHS columns were tested to failure under fire conditions [6-8]. The columns were of circular and square cross sections and were filled with three types of concrete; namely, plain concrete (PC), bar-reinforced concrete $(\mathrm{RC})$ and steel fiber-reinforced concrete (FC). No external fire protection was provided to the steel sections. The present study deals only with plain concrete and bar-reinforced concrete.

When testing columns, it is very important to know the position of the load and the end conditions. Most of the CFSHS columns tested were subjected to a concentric load. Only three columns were tested with an eccentric load. Most of the columns were tested with fixed end conditions. Only four of them had different support conditions.

Computer models have also been developed for predicting the behavior of PC, RC and FC-filled columns in fire $[12,13]$. The models based on moment-curvature relations incorporated realistic stress-stain relationships and the thermal properties for structural steel, concrete, and reinforcing steel at elevated temperatures. The validity of these computer programs has been established by comparing the predictions from the models to test data. The models can account for the important parameters that influence the fire performance of CFSHS columns.

These computer programs were used to carry out detailed parametric studies to generate a large amount of data on the fire resistance of this type of column. 
Based on the relationships between the fire resistance and the above parameters, formulas for the fire resistance of CFSHS columns subjected to axial loading were established empirically (Eq. (1)): one is valid for circular and the other one for square columns. These equations have been rearranged in terms of a maximum load for a desired fire resistance rating, which is most useful for designers.

The fire resistance in minutes is calculated by Eq. (1)

$R=f_{1}^{\prime} *\left[\left(f_{c}^{\prime}+20\right) /\left(L_{K}-1000\right)\right] * D^{2} * \sqrt{D / C}$,

where $R$ is the fire resistance ( $\min$ ), $C$ the applied axial compressive load due to dead and live loads without load factors $(\mathrm{kN}), L_{K}$ the effective length $(\mathrm{mm}), f_{c}{ }^{\prime}$ the specified 28-day concrete strength $(\mathrm{MPa}), D$ the outside diameter or width of the column (mm) and $f_{1}^{\prime}$ the correction factor to account for the type of concrete-filling (PC, RC, and FC), the type of aggregate used (carbonate or siliceous), the percentage of reinforcement, the thickness of concrete cover, and the cross-sectional shape of the SHS column (circular or square), values of which can be found in reference [12].

It must be pointed out that limitations exist on several parameters including an upper limit for applied axial load $C$, as shown in Eq. (2).

$C \leq C_{\max }=\left[\frac{f_{1}^{2} \cdot\left(f_{c}^{\prime}+20\right)^{2}}{R^{2} \cdot\left(L_{K}-1000\right)^{2}}\right] \cdot D^{5}$.

The $C_{\max }$ value should not exceed 1.0 times $C_{r}{ }^{\prime}$ for Steel Hollow Section (SHS) columns filled with plain concrete, 1.7 times $C_{r}{ }^{\prime}$ for SHS columns filled with bar-reinforced concrete and 1.1 times $C_{r}{ }^{\prime}$ for SHS columns filled with steel-fibre reinforced concrete, where $C_{r}{ }^{\prime}$ is the compressive resistance of the concrete core. There are also restrictions imposed on the other parameters $[12,13]$ and as a result some cases cannot be studied. These limitations come from the limits of the experimental study on 58 columns and from the Canadian standards. The data to be introduced are those corresponding to Eqs. (1) and (2).

\subsection{POTFIRE design method}

POTFIRE is a design tool developed by CTICM in France from a model originally proposed in 1992 by COMETUBE but further developed with the collaboration of TNO in the Netherlands.

POTFIRE allows either the evaluation of the fire resistance duration of an unprotected CFSHS column under a known design load, or the evaluation of the ultimate load bearing resistance after a given exposure time to the standard ISO fire. It is also possible to take bending moments into account. It deals with circular, square and rectangular sections.

Three versions of POTFIRE, namely V1.2, V2.0 and V3.0, have been used in this study. The first two are based on the same calculation principles. They only differ in the models used for the thermal and mechanical properties of the materials. V1.2 refers to Annex G of ENV 1994-1-2 [10]. It must be pointed out that the material laws in this Annex $G$ are different from those presented in the core of the Eurocode. V2.0 refers to Annex H of EN 1994-1-2 [11]. POTFIRE V3.0 uses the same material models as V2.0, but the critical buckling load is calculated on the basis of buckling curves as described in EN1994-1-2 [11], and not according to the developments presented here after for V1.2 and V2.0. V1.2 and V2.0 are superseded versions, but they have been used by engineers to design buildings. It is interesting to examine briefly the calculation principles on which versions V1.2, V2.0 and V3.0 are based.

For the first two versions, the Guiaux-Janss method [1] is used to define the axial buckling resistance $N_{f, c r}$ for a column with different materials characterized by non linear stress-strain curves at elevated temperatures. This load must be equal to the sum of the internal forces $N_{f i, R d}$ existing at failure.

$$
\begin{aligned}
& N_{f i, R d}=\sum \frac{\left(A_{s} \cdot \sigma_{s, \theta}\right)}{\gamma_{M, f i, s}}+\sum \frac{\left(A_{c} \cdot \sigma_{c, \theta}\right)}{\gamma_{M, f i, c}}+\sum \frac{\left(A_{a} \cdot \sigma_{a, \theta}\right)}{\gamma_{M, f i, a}}, \\
& N_{f i, c r}=\frac{\pi^{2} *\left[\sum\left(E_{s, \theta} \cdot I_{s}\right)+\sum\left(E_{c, \theta} \cdot I_{c}\right)+\sum\left(E_{a, \theta} \cdot I_{a}\right)\right]}{L_{\theta}^{2}},
\end{aligned}
$$

where $N_{f, c r}$ is the critical or Euler buckling resistance, $N_{f, R d}$ is the sum of the internal forces acting on the total cross section, $L_{\theta}$ is the buckling length in the fire situation, $\sigma_{i, \theta}$ is the stress in material $i$ at the temperature $\theta, E_{i, \theta}$ is the tangent modulus of the stress-strain relationship for material $i$ at temperature $\theta$ and for a stress $\sigma_{i, \theta}$, Ii is the second moment of area of material component $i$, related to the central axis of the composite cross section, $A_{i}$ is the cross-section area of material component $i, \gamma_{M, f, i}$ is the partial safety factor in fire design for material i. $\left(E_{i, \theta} \cdot I_{i}\right)$ and $\left(A_{i} . \sigma_{i, \theta}\right)$ have to be calculated as a summation of all elementary components in the section having the temperature $\theta$ after a fire duration time $t$. The values of $E_{i, \theta}$ and $\sigma_{i, \theta}$ used comply with:

$\varepsilon_{s}=\varepsilon_{c}=\varepsilon_{a}=\varepsilon$, 
where $\varepsilon$ is the axial deformation of the whole column and $\varepsilon_{i}$ is the axial deformation of material component $i$ of the cross-section.

It is therefore assumed that the strains in both concrete and steel are the same, which means that no slipping between steel and concrete occurs. In real structural element, this assumption is not correct. However, in ambient temperature calculations according to Eurocode 4 [9], there is no slipping between the different materials of the CFSHS columns.

In fire situation, experience shows that with rising temperature slipping can occur between the different materials particularly between steel tube SHS and concrete core [20]. This slipping is the result of different deformation and thermal expansion of the individual components of the composite cross-section [20].

Moreover in fire situation, simplified calculations based on the assumption that there is a complete interaction between the different steel and concrete materials are also adopted by Eurocode 4 [10-11].

The design axial buckling resistance must be calculated step-by-step and obtained when:

$N_{f i, c r}=N_{f i, R d}$.

All $\gamma$ factors are taken equal to 1 in the fire situation.

When bending moments are present, i.e. when the column is eccentrically loaded, an equivalent axial load $N_{\text {equ }}$. is calculated in such a way that the column will survive for the same time in a fire when submitted to the real eccentric $\operatorname{load} N_{f i, S d}$ and the fictitious axial load $N_{e q u}$.

$N_{\text {equ. }}=N_{f i, S d} / \varphi_{s} \cdot \varphi_{\delta}$.

In which $\varphi_{S}$ and $\varphi_{\delta}$ are empirically derived parameters to account for the steel reinforcement ratio and the load eccentricity. These are given graphically in EC4 Annex H [11].

The method used by POTFIRE V3.0 is based on the method given in the French National Annex (FNA) of EN 1994-1-2 [11]. The calculation method is divided in two successive steps: firstly the calculation of the temperature field in the composite cross-section after the required fire duration; secondly the calculation of the design buckling load for the temperature field previously obtained, using the design plastic resistance to axial compression of the composite cross-section and specific bucking curves. The temperature field is calculated using the finite differences method with explicit scheme. The formulation is based on a simple and regular discretization of the composite cross-section. Calculations are carried out using the upper limit of thermal conductivity of concrete, specified in EN 1994-1-2 [11], the value 0.7 currently recommended for the emissivity coefficient $\varepsilon_{m}$ of the hollow steel section and the "stress-strain" relationships at elevated temperature of the concrete given in Annex B of EN 1994-1-2 [11]. The design axial buckling load $N_{f, c r}$ of composite columns in fire situation is given by Eq. (8).

$N_{f i, c r}=\chi^{*}\left(\bar{\lambda}_{\theta}\right) \cdot N_{f i, R d}$,

where $N_{f, R d}$ is the design plastic resistance to axial compression in fire situation given by Eq. (3) and $\chi^{*}\left(\bar{\lambda}_{\theta}\right)$ is the reduction factor of an appropriate buckling curve defined as function of the relative slenderness at elevated temperature of the column, the cross-section sizes, the percentage of reinforcement and the fire duration.

For additional information on the thermal analysis, mechanical and thermal properties of materials and the method of determining the reduction factor $\chi^{*}\left(\bar{\lambda}_{\theta}\right)$, it is appropriate to consult the French National Annex of EN 1994-1-2.

The versions of POTFIRE have limitations on several parameters such as the dimensions of the cross section, the buckling length, the percentage of reinforcement, the eccentricity of the axial load, the mechanical characteristics of materials and others. For example, to POTFIRE V3.0, they relate to the column type (square or circular), the size of the hollow section $(100 \mathrm{~mm} \leq$ width $\mathrm{b}$ or diameter $\mathrm{d} \leq 610 \mathrm{~mm})$, the buckling length $(\leq 30 \mathrm{~b}$ or $30 \mathrm{~d})$, the percentage of reinforcements $(\leq 6 \%)$, the load eccentricity $(\geq 0.125 \mathrm{~b}$ (or $\mathrm{d}$ ) and $\leq \mathrm{b}$ (or d)) and for the mechanical properties of each material. The steel yield strength should be specified in accordance with steel grades to EN 10210 [11] or EN 10219 [11], while the class of concrete should be specified between the limits of C20/25 and C60/75. Other limitations can be found in POTFIRE [14]. Moreover the three methods of POTFIRE do not allow calculating ultimate loads when exceeding the fire resistance above the level of R120. In the user's manual POTFIRE [14], clear instructions describe how to introduce the data.

\subsection{SAFIR computer program}

SAFIR is a non-linear numerical code developed at the University of Liege [15]. It is especially suited to the analysis of structures under elevated temperature conditions, although it can also be used to analyze structures under ambient conditions. The program, which is based on the Finite Element Method (FEM), can be used to study the behavior of two and three-dimensional structures. SAFIR 
accommodates various elements for different idealizations, calculation procedures and material models incorporating stress-strain behavior. There is therefore no limit of applicability when using SAFIR. The elements include 2-D SOLID, 3-D SOLID, BEAM, SHELL and TRUSS elements.

Two different material models will be used in SAFIR in this article. The first model is based on the laws contained in ENV 1994-1-2 [10], while the second one incorporates those contained in EN 1994-1-2 [11].

Using the program, the analysis of structures exposed to fire consists of two steps. The first step involves the calculation of the temperature distribution inside the structural members, referred to as "thermal analysis". The second step, named "structural analysis", is carried out in order to determine the mechanical response of the structure due to the thermal effects, since the load is usually assumed to remain constant during the fire.

The thermal analysis is performed while the structure is exposed to fire. In CFSHS columns, a uniform temperature has been assumed over the height of the column. This hypothesis is not consistent with the real conditions observed during laboratory tests. According to Kwasniewski et al. [21], the temperature distribution along the columns tested is not uniform due to the heat transfer at the partially insulated furnace openings.

Thus, thermal analysis can be reduced to a two-dimensional problem of transient heating. The non-steady state $2 \mathrm{D}$ temperature distribution within any cross-section is determined by solving the Fourier thermal conductivity equation.

The temperature field within a given network is established by a finite element method in conjunction with an integration method for time steps. It is assumed that conduction is the main heat transfer mechanism in the hollow steel section and concrete core. Convection and radiation act essentially to transfer heat from the fire environment to the external hollow steel section. In the classical version of SAFIR, the thermal material models are those given in EC4 1-2 [11], but other models can also be used. Therefore the thermal conductivity, specific heat capacity and thermal elongation are temperature dependent. The influence of moisture (assumed as uniformly distributed in the concrete) is treated in a simplified way: the transient temperatures in the concrete are calculated assuming that all moisture evaporates, without any transfer, at temperatures situated within a narrow range, with the heat of evaporation giving a corresponding change in the enthalpy-temperature curve. Therefore during the period of evaporation, all the heat supplied to an element is used for the moisture evaporation until the element is dry.

The discretization for plane sections of different shapes is possible by using triangular and/or quadrilateral elements. For each element the material can be defined separately. Any material can be analyzed provided its physical properties at elevated temperatures are known. The variation of material properties with temperature can be considered. Fig. 1 shows an example of discretization of a circular tube with 8 rebars.

For the structural analysis at elevated temperature, for each calculation, the loads are applied to the structure, described as BEAM, TRUSS and SHELL elements. The temperature history of the structure, due to fire, is read from the files created during the temperature analysis.

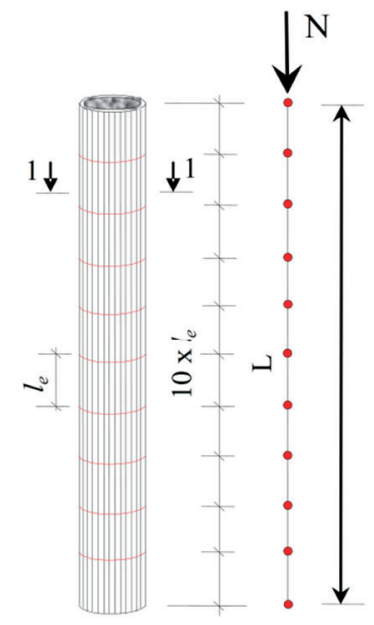

(a)

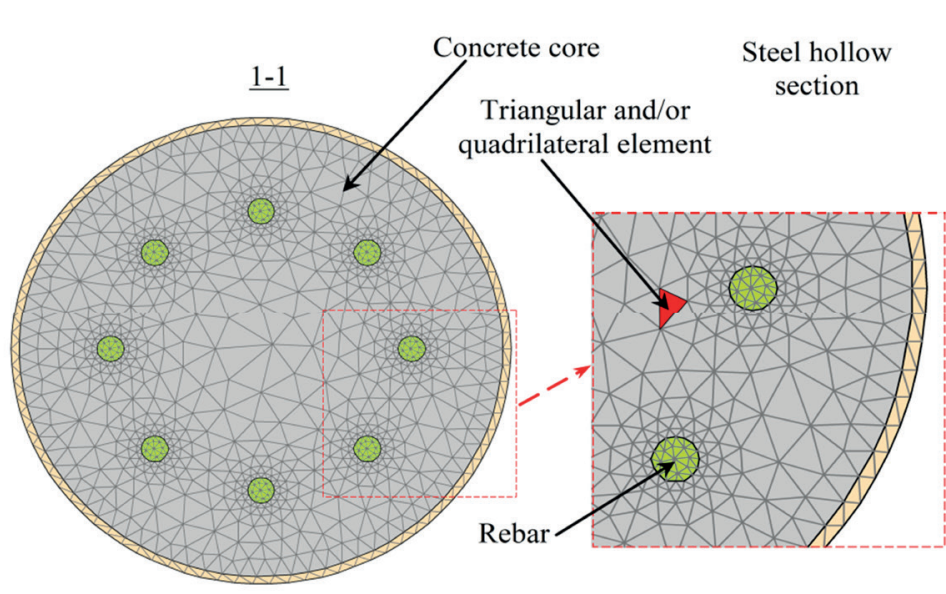

(b)

Fig. 1 Discretization of a circular steel hollow section 219.1x3.6 filled with concrete and containing 8 rebars of 12 mm: (a) discretization of a column in 10 beams le with fiber model; (b) discretization of the cross section (number of nodes: 972; number of triangular elements: 1806) 
As the computation strategy is based on a step-by-step procedure, the following information can be obtained until failure occurs in the structure: the displacement at each node of the structure, the axial and shear forces, and bending moments at integration points in each finite element, the strains, stresses and tangent moduli in each mesh at integration points of each finite element. Information on formulations and hypotheses contained in SAFIR can be found in [15].

\section{Comparative study}

Various comparisons have been made between the three methods, and in one case with experimental results. Although every effort has been made to explain the differences observed, in some cases there are some anomalies.

In a standard fire test, the element is submitted to a certain mechanical load and to other standard conditions (mainly thermal and physical). In fire engineering, two problems must be considered: the estimation of the fire resistance for a given structural element (verification), and the maximum allowable load acting on the element for a prescribed fire resistance time (design). In the comparisons presented here, the possibility of obtaining these two values is examined for each method.

The properties of materials in ambient temperature adopted in this study are: $f_{y}=235 \mathrm{~N} / \mathrm{mm}^{2}$ (yield strength of the hollow steel section HSS), $f_{c 28}=25 \mathrm{~N} / \mathrm{mm}^{2}$ (compressive strength of concrete) and $f_{y}=500 \mathrm{~N} / \mathrm{mm}^{2}$ (yield strength of reinforcement bars).

\subsection{Comparison between SAFIR, POTFIRE and KODUR methods}

In this first study three classical values of circular cross sections have been chosen (Tables 1, 2 and 3). Compared to what has been tested historically in furnace tests [22], the values adopted for strengths at ambient temperature are slightly low. The load is applied axially. Six buckling lengths $L_{b}$ have been considered so that the slenderness ratio of the columns can vary between low and high: sections $406.3 \times 12.5$ with $L_{b}=2 \mathrm{~m}$ have a low slenderness ratio, while sections $219.1 \times 3.6$ with $L_{b}=4.5 \mathrm{~m}$ have a high slenderness ratio. The four standard fire resistance times have been chosen $\left(R_{f}=30 \mathrm{~min}, R_{f}=60 \mathrm{~min}, R_{f}=\right.$ $90 \mathrm{~min}$ and $R_{f}=120 \mathrm{~min}$ ). In this comparison the three versions of POTFIRE and the two material models in SAFIR have been used. For SAFIR, the value prescribed in Eurocode 3 for the geometric imperfection $\left(L_{t} / 300\right)$ has been adopted [23].
The values of axial compression forces listed in Tables 1 to 3 represent the ruin loads calculated by POTFIRE, SAFIR and KODUR methods, for R30, R60, R90 and R120 minutes resistances under standard fire ISO 834.

From these results, KODUR method is not always applicable for example $38 \%, 54 \%$ and $79 \%$ with no results respectively for the sections listed in Tables 1, 2 and 3. This formula has several limitations [12-13]: some are due to the fact that it cannot be applied beyond the experimental results on which it is based, other come from rules contained in Canadian standards. The limitation involved here is related to the load applied on the column during the fire test. It is interesting to look more in detail at the implications of this non applicability. Two extreme cases will be examined: small slenderness ratio $\left(\phi=406.3 \mathrm{~mm}\right.$ with $\left.L_{b}=2 \mathrm{~m}\right)$ and high slenderness ratio $\left(\phi=219.1 \mathrm{~mm}\right.$ with $\left.L_{b}=4 \mathrm{~m}\right)$.

Considering the load ratio, this one can be calculated in two ways: the ratio between the load applied under fire conditions $N_{f i}$ and the critical load under ambient conditions $\mathrm{Ncr}, 20^{\circ} \mathrm{C}$, or the ratio between $N_{f i}$ and the plastic crushing load under ambient conditions $N_{p l, 20^{\circ} \mathrm{C}}$. The second approach is used here. Since $\mathrm{Ncr}, 20^{\circ} \mathrm{C}$ is always smaller than or equal to $N_{p l, 20^{\circ} \mathrm{C}}$, the first ratio is always larger than the second one.

For $f=406.3 \mathrm{~mm}$ and $L_{b}=2 \mathrm{~m}$, the plastic crushing load under ambient conditions is given by $N_{p l, 20^{\circ} \mathrm{C}}=7714 \mathrm{kN}$. If, for example, the values given by SAFIR EN94 are taken as references, the load ratios for the four values of the fire resistance are respectively $0.592,0.406,0.329$ and 0.260 . It is possible to show [16] that $N_{f i} / N_{c r, 20^{\circ} \mathrm{C}}$ cannot exceed 0.7. For classical loading conditions, $N_{f i} / N_{c r, 20^{\circ} \mathrm{C}} \approx 0.5$. As $N_{f i} / N_{c r, 20{ }^{\circ} \mathrm{C}}$ is smaller, the value 0.592 is very high and will in practice never be reached.

The three other ones are medium or even low values. For $R_{f}=120$ with $L_{b}=2 \mathrm{~m}$, Kodur's method is not applicable. It must be pointed out that Kodur's studies were mainly considered with columns in high-rise buildings, which can explain some cases for which the formulas are not applicable.

For $\phi=219.1 \mathrm{~mm}$ and $L_{b}=4 \mathrm{~m}$, the plastic crushing load under ambient conditions is given by $N_{p l, 20^{\circ} \mathrm{C}}=1884 \mathrm{kN}$. Looking at the values given by SAFIR EN94 the following load ratios are considered: $0.154,0.088,0.051$ and 0.026 . If reference is made to $N_{c r, 20^{\circ} \mathrm{C}}$ the load ratio will of course be sensibly higher, as explained here above. In fact, for such a column, it is unrealistic to reach $R_{f}>30 \mathrm{~min}$, even for a small load ratio. For $R_{f}=30 \mathrm{~min}$, Kodur's formula is not applicable. 
Table 1 Comparison between the three methods for axially loaded columns for circular section $219.1 \times 3.6$ with $8 \varnothing 12$

\begin{tabular}{|c|c|c|c|c|c|c|c|}
\hline \multirow{4}{*}{$\begin{array}{l}L_{b} \\
(\mathrm{~m})\end{array}$} & \multirow{4}{*}{$\begin{array}{l}\text { Time } \\
(\mathrm{min})\end{array}$} & \multicolumn{6}{|c|}{ Axial load (kN) } \\
\hline & & \multirow{3}{*}{$\begin{array}{c}\text { V1.2 } \\
\text { ENV } 1994\end{array}$} & \multirow{3}{*}{$\begin{array}{c}\text { POTFIRE } \\
\text { V2.0 } \\
\text { EN } 1994\end{array}$} & \multicolumn{4}{|c|}{ SAFIR } \\
\hline & & & & V3.0 & ENV1994 & EN1994 & KODUR \\
\hline & & & & EN 1994-FNA & Geometric & tion $\mathrm{Lt} / 300$ & \\
\hline \multirow{4}{*}{1} & $30^{\prime}$ & 928 & 884 & 937 & 866 & 785 & $\mathrm{~N} / \mathrm{A}$ \\
\hline & $60^{\prime}$ & 593 & 521 & 608 & 475 & 436 & N/A \\
\hline & $90^{\prime}$ & 197 & 266 & 369 & 255 & 234 & N/A \\
\hline & $120^{\prime}$ & 99 & 114 & 218 & 134 & 118 & 454 \\
\hline \multirow{4}{*}{2} & $30^{\prime}$ & 831 & 874 & 767 & 696 & 626 & N/A \\
\hline & $60^{\prime}$ & 507 & 494 & 461 & 373 & 338 & N/A \\
\hline & $90^{\prime}$ & 164 & 252 & 274 & 204 & 188 & 359 \\
\hline & $120^{\prime}$ & 85 & 107 & 159 & 109 & 99 & 202 \\
\hline \multirow{4}{*}{3} & $30^{\prime}$ & 738 & 750 & 604 & 535 & 481 & N/A \\
\hline & $60^{\prime}$ & 428 & 370 & 336 & 292 & 266 & 454 \\
\hline & $90^{\prime}$ & 136 & 192 & 205 & 162 & 153 & 202 \\
\hline & $120^{\prime}$ & 70 & 84 & 117 & 85 & 81 & 114 \\
\hline \multirow{4}{*}{4} & $30^{\prime}$ & 654 & 576 & 405 & 412 & 371 & N/A \\
\hline & $60^{\prime}$ & 367 & 276 & 248 & 228 & 210 & 291 \\
\hline & $90^{\prime}$ & 113 & 143 & 155 & 126 & 121 & 129 \\
\hline & $120^{\prime}$ & 57 & 63 & 89 & 64 & 63 & 73 \\
\hline \multirow{4}{*}{5} & $30^{\prime}$ & 586 & 457 & 296 & 320 & 290 & N/A \\
\hline & $60^{\prime}$ & 316 & 214 & 191 & 180 & 166 & 202 \\
\hline & $90^{\prime}$ & 97 & 112 & 122 & 99 & 96 & 90 \\
\hline & $120^{\prime}$ & 49 & 50 & 70 & 49 & 49 & 50 \\
\hline \multirow{4}{*}{6} & $30^{\prime}$ & 527 & 375 & 225 & 253 & 230 & N/A \\
\hline & $60^{\prime}$ & 276 & 173 & 152 & 144 & 134 & 148 \\
\hline & $90^{\prime}$ & 83 & 91 & 99 & 80 & 78 & 66 \\
\hline & $120^{\prime}$ & 42 & 42 & 56 & 39 & 38 & 37 \\
\hline
\end{tabular}

N/A: KODUR Not Applicable

Let us now compare the results given by the three versions of POTFIRE methods: V3.0 (EN 1994-FNA) method gives lower results than V1.2 (ENV 1994) and V2.0 (EN 1994) methods especially for the slender columns $\left(L_{b}=4 \mathrm{~m}, 5 \mathrm{~m}\right.$ and $\left.6 \mathrm{~m}\right)$. These lower results seem to be logical since the V3.0 method is based on buckling curves principle.

The first two (V1.2 and V2.0) are based on the determination of the buckling load, but the chosen laws for the mechanical properties of the materials are different which leads to unclear conclusions. Version 3.0 like version 2.0 works with the mechanical properties presented in EN 1994-1-2 [11], but version 3.0 is based on buckling curves and therefore should give smaller values, since geometrical imperfections are integrated in the approach. This is the case for most results, but not for all.
As far as SAFIR method is Concerned, the obtained outcomes in the two versions of the material models ENV 1994-1-2 [10] and EN 1994-1-2 [11], are almost similar in approximately $94 \%$ of all cases.

It is also interesting to compare the two more recent versions of POTFIRE and SAFIR, both taking into account geometrical imperfections. It can be seen that the results given by SAFIR are lower than those given by POTFIRE.

Comparisons can also be made from four diagrams (Figs. 2(a) and 2(b), and Figs. 3(a) and 3(b)) in which the above observations can be easily seen, corresponding to the values mentioned previously for the diameter and the two values of effective length $L_{b}=1 \mathrm{~m}$ and $5 \mathrm{~m} . L_{b}=1 \mathrm{~m}$ seems small, but would represent the effective length if the column was rotationally and laterally fixed at both ends. 
Table 2 Comparison between the three methods for axially loaded columns for circular section $323.9 \times 4$ with $8 \varnothing 16$

\begin{tabular}{|c|c|c|c|c|c|c|c|}
\hline \multirow{4}{*}{$\begin{array}{l}L_{b} \\
(\mathrm{~m})\end{array}$} & \multirow{4}{*}{$\begin{array}{l}\text { Time } \\
(\min )\end{array}$} & \multicolumn{6}{|c|}{ Axial load $(\mathrm{kN})$} \\
\hline & & \multirow{3}{*}{$\begin{array}{c}\text { V1.2 } \\
\text { ENV } 1994\end{array}$} & \multirow{3}{*}{$\begin{array}{c}\text { POTFIRE } \\
\text { V2.0 } \\
\text { EN } 1994\end{array}$} & \multicolumn{4}{|c|}{ SAFIR } \\
\hline & & & & V3.0 & ENV1994 & EN1994 & KODUR \\
\hline & & & & EN 1994-FNA & \multicolumn{2}{|c|}{ Geometric imperfection Lt/300 } & \\
\hline \multirow{4}{*}{1} & $30^{\prime}$ & 2169 & 2208 & 2396 & 2308 & 2190 & $\mathrm{~N} / \mathrm{A}$ \\
\hline & $60^{\prime}$ & 1731 & 1643 & 1928 & 1647 & 1652 & $\mathrm{~N} / \mathrm{A}$ \\
\hline & $90^{\prime}$ & 1070 & 1169 & 1514 & 1168 & 1225 & $\mathrm{~N} / \mathrm{A}$ \\
\hline & $120^{\prime}$ & 592 & 799 & 1176 & 810 & 875 & N/A \\
\hline \multirow{4}{*}{2} & $30^{\prime}$ & 2129 & 2208 & 2276 & 2140 & 2015 & N/A \\
\hline & $60^{\prime}$ & 1731 & 1643 & 1770 & 1443 & 1428 & $\mathrm{~N} / \mathrm{A}$ \\
\hline & $90^{\prime}$ & 1070 & 1169 & 1339 & 965 & 996 & N/A \\
\hline & $120^{\prime}$ & 592 & 799 & 1019 & 648 & 679 & 1426 \\
\hline \multirow{4}{*}{3} & $30^{\prime}$ & 2031 & 2084 & 2126 & 1952 & 1821 & N/A \\
\hline & $60^{\prime}$ & 1647 & 1525 & 1582 & 1231 & 1200 & $\mathrm{~N} / \mathrm{A}$ \\
\hline & $90^{\prime}$ & 1023 & 1080 & 1151 & 788 & 794 & 1426 \\
\hline & $120^{\prime}$ & 584 & 724 & 858 & 516 & 524 & 802 \\
\hline \multirow{4}{*}{4} & $30^{\prime}$ & 1936 & 2049 & 1941 & 1747 & 1616 & N/A \\
\hline & $60^{\prime}$ & 1546 & 1454 & 1378 & 1032 & 988 & $\mathrm{~N} / \mathrm{A}$ \\
\hline & $90^{\prime}$ & 939 & 1005 & 972 & 645 & 634 & 913 \\
\hline & $120^{\prime}$ & 511 & 668 & 711 & 415 & 410 & 513 \\
\hline \multirow{4}{*}{5} & $30^{\prime}$ & 1844 & 2046 & 1733 & 1524 & 1403 & $\mathrm{~N} / \mathrm{A}$ \\
\hline & $60^{\prime}$ & 1440 & 1429 & 1180 & 861 & 811 & 1426 \\
\hline & $90^{\prime}$ & 850 & 974 & 815 & 534 & 514 & 634 \\
\hline & $120^{\prime}$ & 445 & 647 & 567 & 341 & 332 & 356 \\
\hline \multirow{4}{*}{6} & $30^{\prime}$ & 1741 & 1951 & 1520 & 1289 & 1187 & N/A \\
\hline & $60^{\prime}$ & 1325 & 1239 & 1004 & 724 & 673 & 1048 \\
\hline & $90^{\prime}$ & 764 & 824 & 646 & 451 & 427 & 466 \\
\hline & $120^{\prime}$ & 387 & 535 & 448 & 290 & 279 & 262 \\
\hline
\end{tabular}

N/A: KODUR Not Applicable
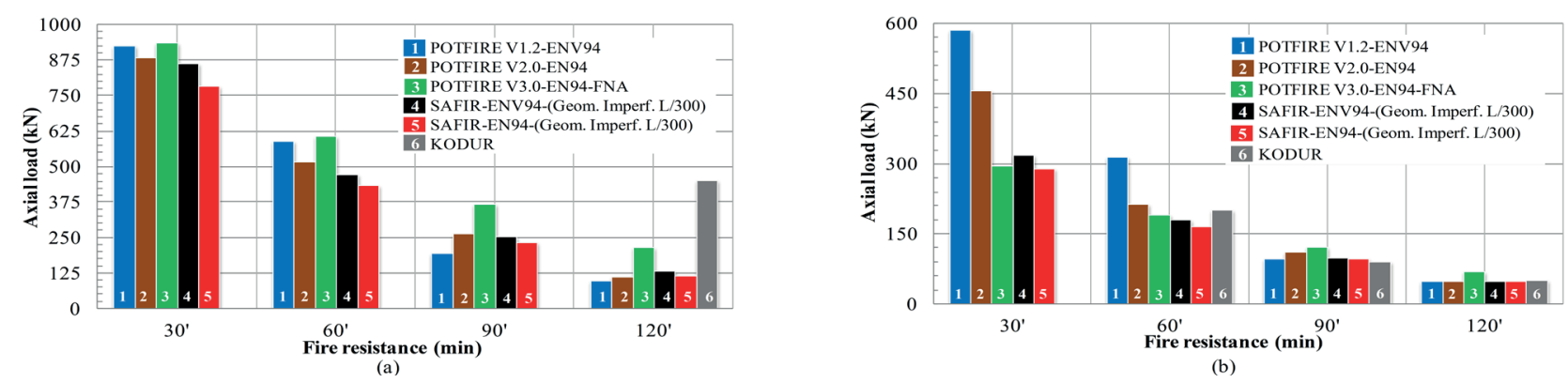

Fig. 2 Comparison between the results of the different methods for the case circular $219.1 \times 3.6$ with $8 \varnothing 12, \rho=2.56 \%$. (a) $L_{b}=1 \mathrm{~m}$. (b) $L_{b}=5 \mathrm{~m}$
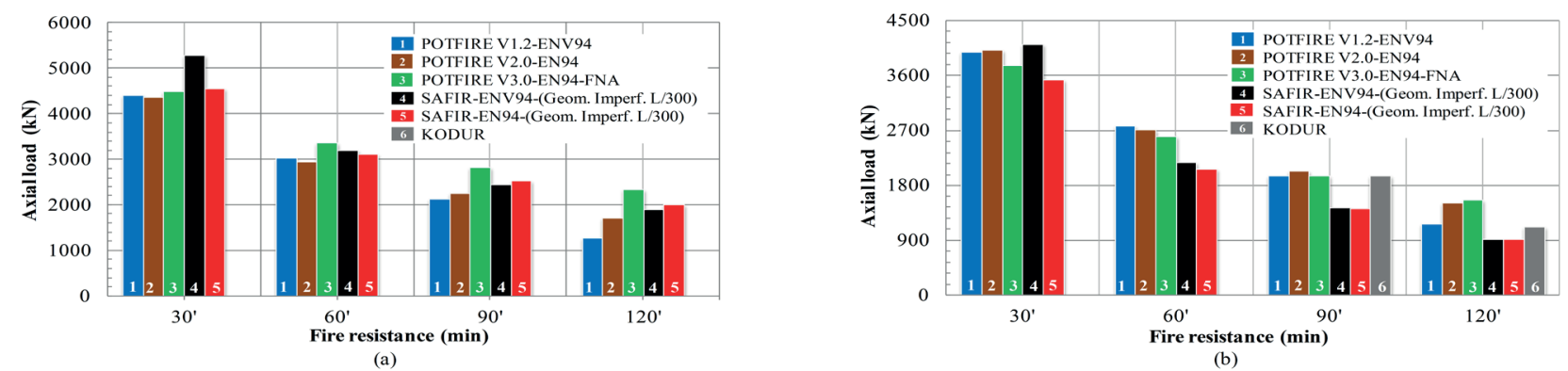

Fig. 3 Comparison between the results of the different methods for the case Circular $406.3 \times 12.5$ with $8 \varnothing 20, \rho=2.2 \%$. (a) $L_{b}=1 \mathrm{~m}$. (b) $L_{b}=5 \mathrm{~m}$ 
Table 3 Comparison between the three methods for axially loaded columns for circular section $406.3 \times 12.5$ with $8 \varnothing 20$

\begin{tabular}{|c|c|c|c|c|c|c|c|}
\hline \multirow{4}{*}{$\begin{array}{l}L_{b} \\
(\mathrm{~m})\end{array}$} & \multirow{4}{*}{$\begin{array}{l}\text { Time } \\
(\min )\end{array}$} & \multicolumn{6}{|c|}{ Axial load (kN) } \\
\hline & & \multirow{3}{*}{$\begin{array}{c}\text { V1.2 } \\
\text { ENV } 1994\end{array}$} & \multirow{3}{*}{$\begin{array}{c}\text { POTFIRE } \\
\text { V2.0 } \\
\text { EN } 1994 \\
\end{array}$} & \multicolumn{4}{|c|}{ SAFIR } \\
\hline & & & & V3.0 & ENV1994 & EN1994 & KODUR \\
\hline & & & & EN 1994-FNA & Geometric i & tion $\mathrm{Lt} / 300$ & \\
\hline \multirow{4}{*}{1} & $30^{\prime}$ & 4408 & 4378 & 4497 & 5282 & 4565 & N/A \\
\hline & $60^{\prime}$ & 3035 & 2959 & 3372 & 3217 & 3131 & N/A \\
\hline & $90^{\prime}$ & 2134 & 2257 & 2825 & 2458 & 2540 & N/A \\
\hline & $120^{\prime}$ & 1270 & 1712 & 2338 & 1889 & 2010 & N/A \\
\hline \multirow{4}{*}{2} & $30^{\prime}$ & 4365 & 4378 & 4359 & 5052 & 4354 & N/A \\
\hline & $60^{\prime}$ & 3035 & 2959 & 3221 & 2987 & 2893 & N/A \\
\hline & $90^{\prime}$ & 2134 & 2257 & 2639 & 2218 & 2278 & N/A \\
\hline & $120^{\prime}$ & 1270 & 1712 & 2167 & 1653 & 1759 & N/A \\
\hline \multirow{4}{*}{3} & $30^{\prime}$ & 4252 & 4331 & 4196 & 4780 & 4106 & N/A \\
\hline & $60^{\prime}$ & 3006 & 2953 & 3043 & 2734 & 2635 & N/A \\
\hline & $90^{\prime}$ & 2134 & 2257 & 2429 & 1933 & 1976 & N/A \\
\hline & $120^{\prime}$ & 1270 & 1712 & 1975 & 1384 & 1457 & N/A \\
\hline \multirow{4}{*}{4} & $30^{\prime}$ & 4121 & 4154 & 4000 & 4473 & 3828 & N/A \\
\hline & $60^{\prime}$ & 2902 & 2804 & 2837 & 2461 & 2358 & N/A \\
\hline & $90^{\prime}$ & 2062 & 2167 & 2199 & 1665 & 1676 & N/A \\
\hline & $120^{\prime}$ & 1247 & 1628 & 1767 & 1138 & 1169 & 1594 \\
\hline \multirow{4}{*}{5} & $30^{\prime}$ & 3989 & 4013 & 3767 & 4106 & 3525 & N/A \\
\hline & $60^{\prime}$ & 2783 & 2710 & 2604 & 2180 & 2072 & N/A \\
\hline & $90^{\prime}$ & 1963 & 2035 & 1962 & 1422 & 1409 & 1968 \\
\hline & $120^{\prime}$ & 1158 & 1505 & 1557 & 910 & 911 & 1107 \\
\hline \multirow{4}{*}{6} & $30^{\prime}$ & 3868 & 3992 & 3497 & 3625 & 3173 & N/A \\
\hline & $60^{\prime}$ & 2659 & 2673 & 2356 & 1907 & 1794 & N/A \\
\hline & $90^{\prime}$ & 1856 & 1965 & 1732 & 1188 & 1135 & 1446 \\
\hline & $120^{\prime}$ & 1065 & 1445 & 1360 & 736 & 716 & 813 \\
\hline
\end{tabular}

N/A: KODUR Not Applicable

For $\phi=219.1$ with $L_{b}=1 \mathrm{~m}$ the differences are not negligible and correspond to what has been discussed here above. For $L_{b}=5 \mathrm{~m}$ two values are much higher for $R_{f}=30$ $\min$ [14] and one for $R_{f}=60 \mathrm{~min}$ [14]. The other results are close to each other.

For $\phi=406.3$ with $L_{b}=1 \mathrm{~m}$, SAFIR ENV94 gives higher values for $R_{f}=30 \mathrm{~min}$, while POTFIRE V3.0 gives higher values for the three other cases. For $L_{b}=5 \mathrm{~m}$ the differences are not negligible, but it is not easy to draw clear conclusions in this case.

\subsection{Comparison with experimental results}

In order to further consider the results of the three methods, the predictions have been compared with test results obtained in various laboratories and described in detail in [3-4].

The main characteristics of the profiles are reproduced in Table 4. In the designation of columns (e.g. SB-260x6.3-8Ø10), the first letter (S) represents section shape (square), the second letter (P, B) denotes concrete-filling type (plain and bar-reinforced concrete), the first number (260) denotes the width of the Steel Hollow Section (SHS), the second number (6.3) denotes the thickness of the tube and in the last term (8Ø10), numbers 8 and 10 respectively denotes the number and the diameter of the rebars.

All columns are axially loaded. All sections are square $260 \times 260 \times 6.3 \mathrm{~mm}$ with reinforcement ratios of 0,1 and $2 \%$ approximately.

Regarding the loads applied, it is well-known that the fire resistance is much less without rebars than when rebars are present.

All the columns presented here have a total length $L_{t}=3.60 \mathrm{~m}$. The Fig. 4 shows the loading device and the calculation scheme of the tested column. At the bottom, a plate is welded to the tube and the whole is set on the support. At the top the load is transmitted by two jacks as indicated, the whole being set on a plate. 


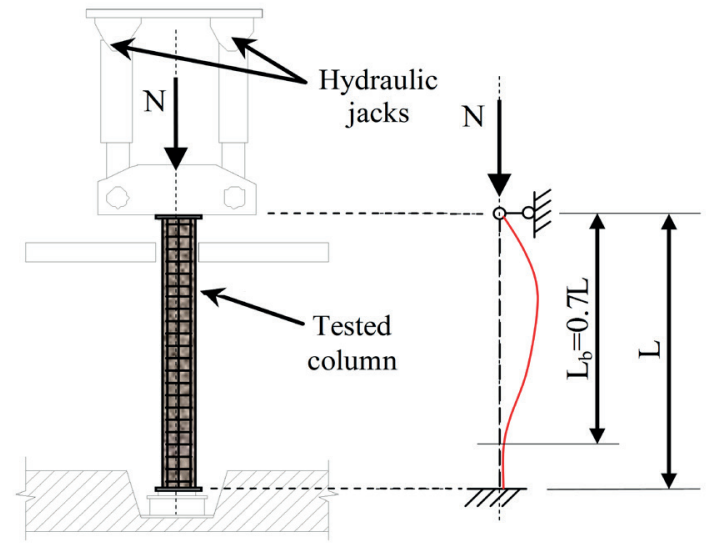

(a)

Fig. 4 (a) Loading device, (b) calculation scheme of the tested column

With this type of device the columns are not hinged and a partial rotational restraint exists at both ends, which is rather difficult to evaluate. In [3] some considerations have led the author to adopt $L_{b}=0.7 L_{t}=2.52 \mathrm{~m}$ although this is recognized as being somewhat uncertain. To explain the value proposed, it must be pointed out that the partial rotational restraint in closer to fixed conditions than to hinged ones. However, adopting for $L_{b}$ a value close to $0.5 \mathrm{Lt}$ would be on the unsafe side. Therefore the value $L_{b}=0.7 L_{t}$ has been proposed. This value has also been adopted in this study.

It can be noticed that the experimental results display a significant scatter. For the tests without rebars the fire resistance varies between 86 and $134 \mathrm{~min}$. For $1 \%$ reinforcement, the values are closer (62 and $66 \mathrm{~min})$, while for $2 \%$ they differ ( 89 and $109 \mathrm{~min}$ ). Though these tests have been performed in various laboratories, the differences can be considered as large. For $2 \%$ reinforcement the difference ( $20 \mathrm{~min} \approx 20 \%$ of the fire resistance time) can be considered as sensible. This explains why it is very difficult to propose theoretical and numerical models for the evaluation of the fire resistance of columns based only on experimental results and why it is important to undertake a comparison between experimental and theoretical predictions.

Concerning SAFIR predictions, only the most recent version of the material model has been used, but three values of the geometrical imperfections have been considered. Though the columns are centrically loaded there is always some geometric imperfection, in practice, and the evaluation on the basis of the crushing load is somewhat on the unsafe side.

On the other hand considering an imperfection $L_{t} / 300$, like the one recommended in EN 1994-1-2 [11], might be too conservative. If the value adopted for the imperfection in the numerical simulations is higher than the real

one, the value calculated will be lower than the true one, and is therefore too conservative. From observations made during tests performed at the University of Liege on rather similar types of profiles, it has been concluded that the real imperfections are very small and close to $L_{t} / 1000$ [16]. Therefore calculations with an imperfection $L_{t} / 1000$ have also been performed, and this should be considered as the most appropriate assumption for the simulation.

For POTFIRE, the three versions have been used. Versions V1.2 and V2.0 give results close to each other. For Version V3.0 the values differ. The difference is significant for the plain concrete case and V3.0 gives smaller values since geometrical imperfections are taken into account. When rebars are present, the differences are small, but the values given by V3.0 are higher, which is surprising.

Concerning Kodur's method the values are closer to experimental results, but it can be noticed that two values are higher than experimental results, the difference being significant in one case (close to $15 \%$ ).

Kodur's formulas have been obtained from a calibration with 58 test results. Almost all (54 out of 58) have been made with fixed end conditions, and it is well-known that in this case high values of the fire resistance time are obtained, as the influence of geometrical imperfections is negligible. This explains why on one side results given by Kodur may be rather close to experimental ones. On the other side they may be unsafe when applied to columns hinged or with partial restraints at both ends, where geometrical imperfections may have a significant effect.

A few diagrams are presented in order to illustrate these conclusions. Fig. 5 displays all the results presented in Table 4. The test results are situated on the diagonal 0A. All results are on the safe side except the two from Kodur, as mentioned previously and two from SAFIR.

Concerning SAFIR two values are higher than experimental results, but the value with no geometric imperfection has no significance, since it has been decided to adopt $L_{t} / 1000$ for the geometric imperfection.

Comparing the results from SAFIR for the three values of the geometric imperfection, it can be seen that this parameter has a significant influence.

For two values of experimental results ( 86 and $98 \mathrm{~min}$ - plain concrete) the values given by SAFIR $\left(L_{t} / 1000\right)$ and Kodur are reasonably well in agreement with test results, while all the results given by POTFIRE are with wider safety margin.

For the other two values (133 and $134 \mathrm{~min}$ ), all the calculated values are with bigger safety margin. 


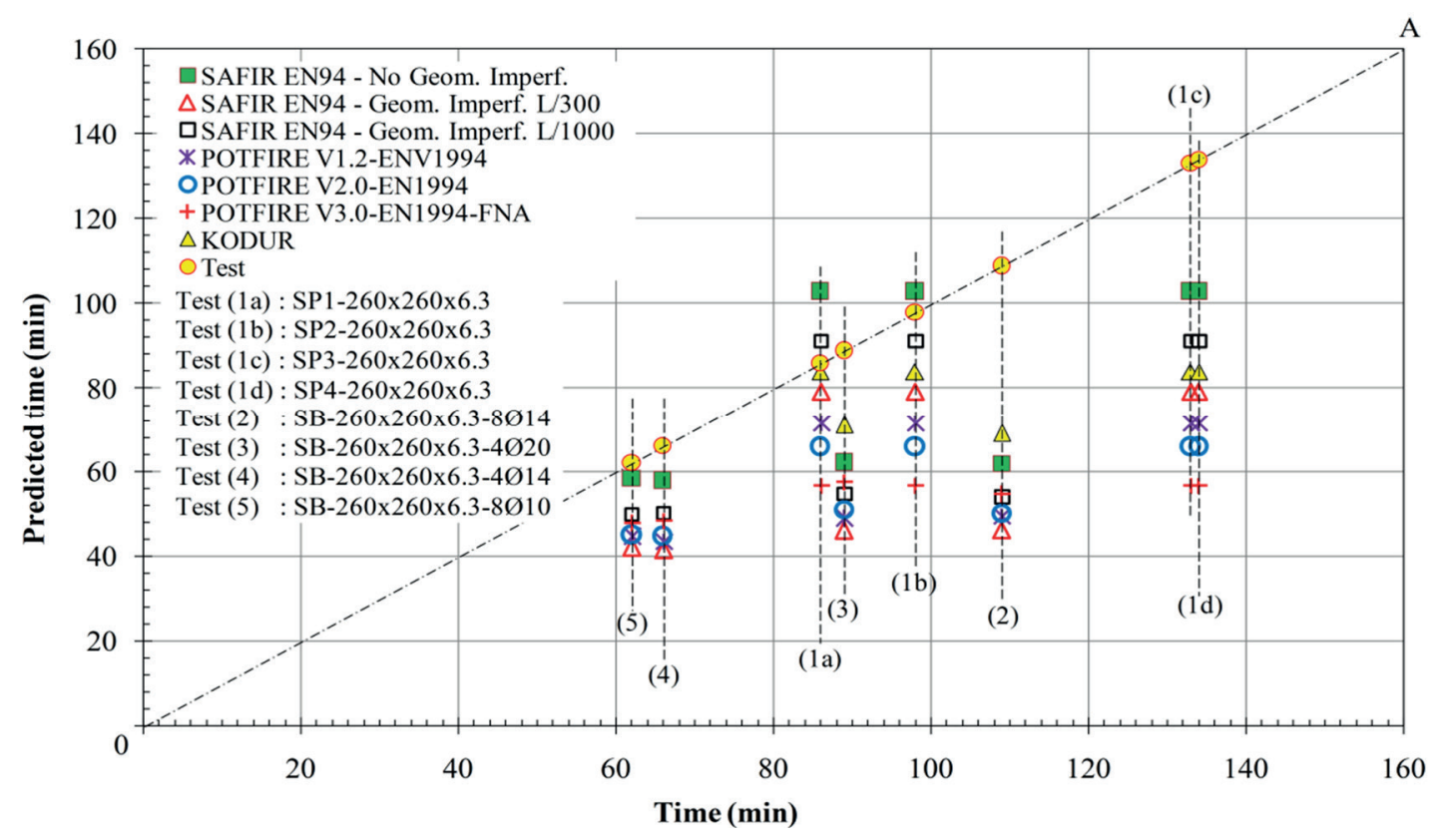

Fig. 5 Comparison between all results (Test, SAFIR, POTFIRE and KODUR)

Table 4 Comparison between the results of the three methods and test results

\begin{tabular}{|c|c|c|c|c|c|c|c|c|c|c|}
\hline \multirow{4}{*}{$\begin{array}{l}\text { Section } \\
\text { type }\end{array}$} & \multirow{4}{*}{$\begin{array}{c}\rho \\
(\%)\end{array}$} & \multirow{4}{*}{$\begin{array}{c}C \\
(\mathrm{kN})\end{array}$} & \multicolumn{8}{|c|}{ Fire resistance $(\mathrm{min})$ with $L_{b}=2.52 \mathrm{~m}$} \\
\hline & & & \multirow{3}{*}{ Test } & \multirow{2}{*}{\multicolumn{3}{|c|}{$\begin{array}{c}\text { SAFIR EN1994 } \\
\text { Geometric imperfection }\end{array}$}} & \multicolumn{3}{|c|}{ POTFIRE } & \multirow{3}{*}{ KODUR } \\
\hline & & & & & & & V1.2 & V2.0 & V3.0 & \\
\hline & & & & No & $L_{t} / 300$ & $L_{t} / 1000$ & $\begin{array}{l}\text { ENV } \\
1994\end{array}$ & $\begin{array}{c}\text { EN } \\
1994\end{array}$ & $\begin{array}{c}\text { EN } \\
1994 \\
\text { FNA }\end{array}$ & \\
\hline SP1-260x6.3 & 0 & 800 & $86^{x}$ & \multirow{4}{*}{103} & \multirow{4}{*}{79} & \multirow{4}{*}{91} & \multirow{4}{*}{$72^{+}$} & \multirow{4}{*}{$66^{+}$} & \multirow{4}{*}{$57^{+}$} & \multirow{4}{*}{84} \\
\hline SP2-260x6.3 & 0 & 800 & $98^{\mathrm{x}}$ & & & & & & & \\
\hline SP3-260x6.3 & 0 & 800 & $133^{x}$ & & & & & & & \\
\hline SP4-260x6.3 & 0 & 800 & $134^{x}$ & & & & & & & \\
\hline SB-260x6.3-8Ø10 & 1 & 1500 & 62 & 58 & 42 & 50 & $45^{+}$ & $45^{+}$ & $48^{+}$ & $*$ \\
\hline SB-260x6.3-8Ø14 & 2 & 1500 & 109 & 62 & 46 & 54 & $50^{+}$ & $50^{+}$ & $55^{+}$ & 69 \\
\hline SB-260x6.3-4Ø14 & 1 & 1500 & 66 & 58 & 41 & 50 & $44^{+}$ & $45^{+}$ & $48^{+}$ & $*$ \\
\hline SB-260x6.3-4Ø20 & 2 & 1500 & 89 & 62 & 46 & 55 & $49^{+}$ & $51^{+}$ & $58^{+}$ & 71 \\
\hline
\end{tabular}

*: \% reinforcement $<1.5 \%$ according to the Canadian standards $1.5 \% \leq \rho \leq 5 \%$; +values obtained by linear interpolation;

${ }^{\mathrm{x}}$ values from 4 tests in various laboratories

It may be interesting to adopt another way of representation. This has been done for two particular cases of experimental results (plain concrete $R_{f}=98 \mathrm{~min}$; concrete with rebars $R_{f}=66 \mathrm{~min}$ ) (Figs. 6 and 7).

Coming back to Fig. 5 , it can be seen that, for the examples with rebars the results vary from one case to another. For two tests (8Ø14 and 4Ø20), all theoretical results are with wider safety margin, which is not the case for the two other tests (8Ø10 and 4Ø14). The best estimation is given by Kodur for two cases, but for the two other cases the calculated values are on the unsafe side. It can also be seen that the most significant values of SAFIR and POTFIRE (SAFIR EN94- $L_{t} / 1000$ and POTFIRE V3.0) are close to each other.

Also, according to Kwasniewski et al. [24], the main difference's sources between numerical and experimental results, particularly in the post-buckling phase, are due to simplified numerical material model and complexity of actual mechanical support conditions. Kwasniewski et al. [21] also found that the postponed buckling observed during tests is due to non-uniform temperature distribution along the columns tested. Their study [21-24] shows 


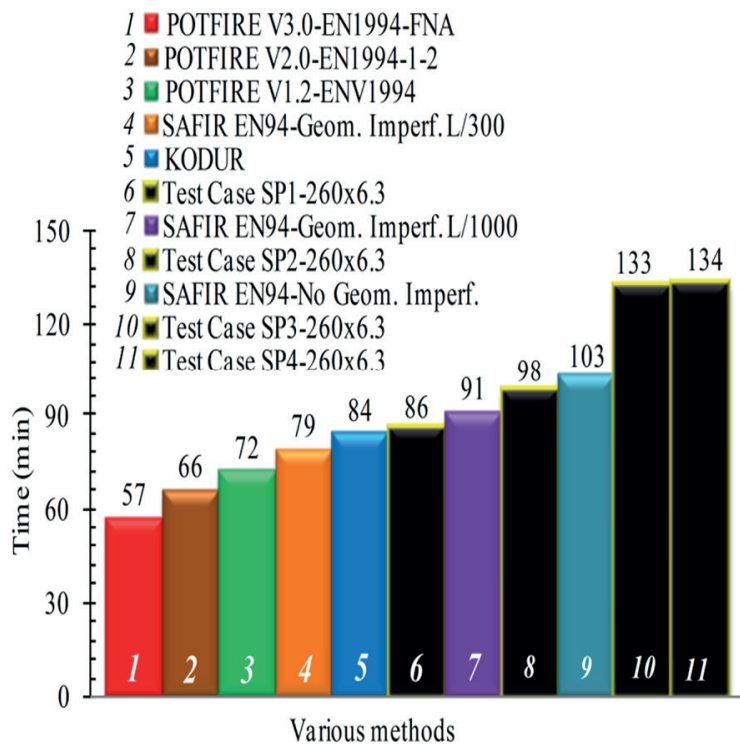

Fig. 6 Comparison between the results for the case SP-260x6.3. Applied load $800 \mathrm{kN}$

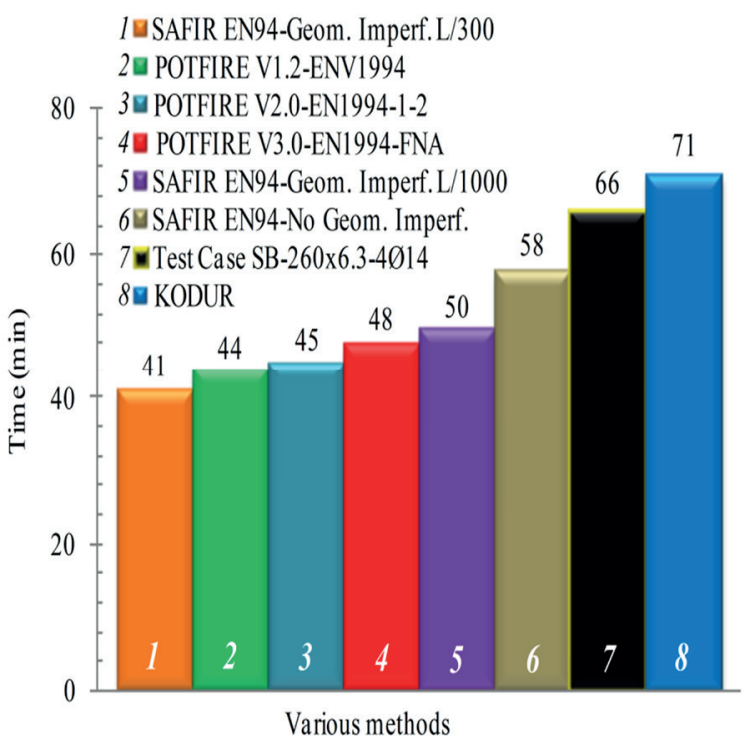

Fig. 7 Comparison between the results for the case SB-260x6.3-4Ø14. Applied load $1500 \mathrm{kN}$

that the modeling factors influence numerical results, such as magnitude of imperfections and therefore it is not possible to better correlate numerical results with existing experimental data.

\subsection{Comparison between the results of two methods for eccentric loads}

In the two preceding comparisons the columns were axially loaded. It has been found interesting to compare the methods for eccentric loads. For this purpose the circular section 323.9 with $8 \varnothing 16$ has been examined using one material model with SAFIR and two versions of POTFIRE. Three values of the eccentricity have been chosen: 10, 20 and 50 $\mathrm{mm}$. The calculations have been performed for two values of the buckling length: $L_{b}=1$ and $4.5 \mathrm{~m}$, respectively for low and high slenderness ratios (see Tables 5 and 6).

It must be pointed out that Kodur's method is not applicable to this case, since the method assumes concentric loading.

On the other hand Versions V1.2 and V2.0 of POTFIRE have been used since it is not possible to introduce an eccentricity with version V3.0.

Concerning SAFIR, no geometrical imperfection has been introduced. It is assumed that it is contained in the external eccentricity.

The complete set of results is given in Tables 5 and 6 , $R_{f}$ is the fire resistance duration time of the column, Load is the applied eccentric compression force. In Table 6, the value of $2888 \mathrm{kN}$ is the $10 \mathrm{~mm}$ eccentric compression load which the column can withstand at ambient temperature.

The procedure consists of reducing this compression Load and calculating progressively for each adopted value the resistance time $R_{f}$. For example, in Table $6,2400 \mathrm{kN}$, $1600 \mathrm{kN}$ and $400 \mathrm{kN}$ are the $10 \mathrm{~mm}$ eccentric compression loads which can the column withstand respectively after 10, 25 and 103 minutes of heating under a standard fire.

It is also possible to analyze the results obtained from diagrams giving the admissible load versus the fire resistance duration time (Figs. 8 and 9) for the three calculation methods.

From the results obtained for the slender column $\left(L_{b}=4.5 \mathrm{~m}\right)$, the three methods give almost the same compression force values for the same heating time particularly for the eccentricities 20 and $50 \mathrm{~mm}$ and overheating exceeding 30 minutes. For the weak slender column $\left(L_{b}=1 \mathrm{~m}\right)$, the two versions of POTFIRE give fairly similar results whereas those of SAFIR are higher. Further detailed discussion was given in Section 3.3.

Figs. 8(a) to 8(c) correspond to the case $L_{b}=1 \mathrm{~m}$, i.e. a column with a small slenderness ratio. The diagrams show that the two versions of POTFIRE give results close to each other, while the values given by SAFIR are higher. This is true for all values of the fire resistance time, and for the three values of the eccentricity.

The results are not surprising. The two versions of POTFIRE (V1.2 and V2.0) are very similar. They usually give results with wider safety margin (Table 4 and Fig. 5). Therefore the admissible load given by POTFIRE will be in most cases smaller than the one given by SAFIR for the prescribed fire resistance duration time. 
Table 5 Comparison between two methods for eccentrical loads for circular section 323.9x4 with $8 \varnothing 16$ - $L_{b}=1$ m without geometrical imperfection

\begin{tabular}{|c|c|c|c|c|c|c|c|c|c|c|c|c|c|c|c|c|c|}
\hline \multicolumn{6}{|c|}{ SAFIR EN1994 } & \multicolumn{6}{|c|}{ POTFIRE V2.0 - EN1994 } & \multicolumn{6}{|c|}{ POTFIRE V1.2 - ENV1994 } \\
\hline \multicolumn{6}{|c|}{ Eccentricity } & \multicolumn{6}{|c|}{ Eccentricity } & \multicolumn{6}{|c|}{ Eccentricity } \\
\hline \multicolumn{2}{|c|}{$10 \mathrm{~mm}$} & \multicolumn{2}{|c|}{$20 \mathrm{~mm}$} & \multicolumn{2}{|c|}{$50 \mathrm{~mm}$} & \multicolumn{2}{|c|}{$10 \mathrm{~mm}$} & \multicolumn{2}{|c|}{$20 \mathrm{~mm}$} & \multicolumn{2}{|c|}{$50 \mathrm{~mm}$} & \multicolumn{2}{|c|}{$10 \mathrm{~mm}$} & \multicolumn{2}{|c|}{$20 \mathrm{~mm}$} & \multicolumn{2}{|c|}{$50 \mathrm{~mm}$} \\
\hline $\begin{array}{l}\text { Load } \\
(\mathrm{kN})\end{array}$ & $\begin{array}{c}\mathrm{Rf} \\
(\mathrm{min})\end{array}$ & $\begin{array}{l}\text { Load } \\
(\mathrm{kN})\end{array}$ & $\begin{array}{c}\mathrm{Rf} \\
(\mathrm{min})\end{array}$ & $\begin{array}{l}\text { Load } \\
(\mathrm{kN})\end{array}$ & $\begin{array}{c}\mathrm{Rf} \\
(\mathrm{min})\end{array}$ & $\begin{array}{l}\text { Load } \\
(\mathrm{kN})\end{array}$ & $\begin{array}{c}\mathrm{Rf} \\
(\mathrm{min})\end{array}$ & $\begin{array}{l}\text { Load } \\
(\mathrm{kN})\end{array}$ & $\begin{array}{c}\mathrm{Rf} \\
(\mathrm{min})\end{array}$ & $\begin{array}{l}\text { Load } \\
(\mathrm{kN})\end{array}$ & $\begin{array}{c}\mathrm{Rf} \\
(\mathrm{min})\end{array}$ & $\begin{array}{l}\text { Load } \\
(\mathrm{kN})\end{array}$ & $\begin{array}{c}\mathrm{Rf} \\
\text { (min) }\end{array}$ & $\begin{array}{l}\text { Load } \\
(\mathrm{kN})\end{array}$ & $\begin{array}{c}\mathrm{Rf} \\
(\mathrm{min})\end{array}$ & $\begin{array}{l}\text { Load } \\
(\mathrm{kN})\end{array}$ & $\begin{array}{c}\mathrm{Rf} \\
(\mathrm{min})\end{array}$ \\
\hline 50 & 360 & 50 & 360 & 50 & 360 & 50 & 361 & 50 & 344 & 50 & 312 & 50 & 384 & 50 & 369 & 50 & 328 \\
\hline 100 & 360 & 100 & 360 & 100 & 357 & 100 & 267 & 100 & 252 & 100 & 224 & 100 & 259 & 100 & 237 & 100 & 204 \\
\hline 200 & 320 & 200 & 308 & 200 & 272 & 200 & 193 & 200 & 182 & 200 & 164 & 200 & 171 & 200 & 163 & 200 & 147 \\
\hline 300 & 271 & 300 & 258 & 300 & 220 & 300 & 162 & 300 & 156 & 300 & 141 & 300 & 145 & 300 & 137 & 300 & 120 \\
\hline 400 & 236 & 400 & 223 & 400 & 180 & 400 & 146 & 400 & 138 & 400 & 121 & 400 & 126 & 400 & 118 & 400 & 104 \\
\hline 600 & 184 & 600 & 169 & 600 & 144 & 600 & 119 & 600 & 110 & 600 & 89 & 600 & 103 & 600 & 97 & 600 & 85 \\
\hline 800 & 154 & 800 & 144 & 800 & 117 & 800 & 96 & 800 & 86 & 800 & 64 & 800 & 89 & 800 & 83 & 800 & 68 \\
\hline 1000 & 137 & 1000 & 123 & 1000 & 93 & 1000 & 77 & 1000 & 67 & 1000 & 42 & 1000 & 77 & 1000 & 70 & 1000 & 41 \\
\hline 1200 & 115 & 1200 & 104 & 1200 & 72 & 1200 & 61 & 1200 & 50 & 1200 & 27 & 1200 & 67 & 1200 & 50 & 1200 & 24 \\
\hline 1400 & 99 & 1400 & 87 & 1400 & 50 & 1400 & 47 & 1400 & 35 & 1400 & 19 & 1400 & 46 & 1400 & 31 & 1400 & 15 \\
\hline 1600 & 83 & 1600 & 71 & 1600 & 33 & 1600 & 34 & 1600 & 25 & 1600 & 13 & 1600 & 30 & 1600 & 22 & 1600 & 2 \\
\hline 1800 & 69 & 1800 & 53 & 1800 & 23 & 1800 & 25 & 1800 & 19 & 1800 & 6 & 1800 & 22 & 1800 & 15 & 1610 & 1 \\
\hline 2000 & 52 & 2000 & 38 & 2000 & 18 & 2000 & 20 & 2000 & 15 & 1850 & 3 & 2000 & 16 & 2000 & 7 & 1612 & 0 \\
\hline 2200 & 38 & 2200 & 27 & 2200 & 14 & 2200 & 16 & 2200 & 9 & 1855 & 2 & 2200 & 10 & 2050 & 3 & - & - \\
\hline 2400 & 28 & 2400 & 22 & 2400 & 6 & 2400 & 11 & 2300 & 6 & 1859 & 1 & 2300 & 5 & 2060 & 2 & - & - \\
\hline 2600 & 22 & 2600 & 18 & 2500 & 2 & 2600 & 6 & 2375 & 3 & 1862 & 0 & 2320 & 3 & 2070 & 1 & - & - \\
\hline 2800 & 19 & 2800 & 14 & 2520 & 1 & 2700 & 2 & 2395 & 1 & - & - & 2340 & 1 & 2075 & 0 & - & - \\
\hline 3000 & 16 & 3000 & 4 & 2523 & 0 & 2708 & 1 & 2398 & 0 & - & - & 2345 & 0 & - & - & - & - \\
\hline 3100 & 14 & 3050 & 3 & - & - & 2709 & 0 & - & - & - & - & - & - & - & - & - & - \\
\hline 3200 & 10 & 3075 & 1 & - & - & - & - & - & - & - & - & - & - & - & - & - & - \\
\hline 3300 & 3 & 3089 & 0 & - & - & - & - & - & - & - & - & - & - & - & - & - & - \\
\hline 3326 & 0 & - & - & - & - & - & - & - & - & - & - & - & - & - & - & - & - \\
\hline
\end{tabular}

The case $L_{b}=4.5 \mathrm{~m}$ is displayed in Figs. 9(a) to 9(c) and corresponds to a high slenderness ratio. It can be seen that the results given here by the three approaches are rather similar, except for very small values of $R_{f}$ corresponding to high loads. The same observation can be made for the three values of the eccentricity.

The following explanation is given for these differences. SAFIR and POTFIRE do not work in the same way. SAFIR is a numerical code that simulates the behavior of the structural element up to failure on the basis of the principles of structural mechanics. POTFIRE has first been established for concentric loaded columns on the basis of the buckling load. For eccentric loads the procedure proposed is somewhat artificial.

It consists of replacing the eccentric load by a concentric one affected by a coefficient of correction in which only three parameters are considered: the eccentricity, the slenderness and the percentage of steel. However, other factors not taken into account may influence the effect of eccentricity, e.g. the concrete strength, the concrete cover to bar reinforcement. If the concrete cover increases the bending moment capacity decreases, and in the same way the fire resistance.

Furthermore, for the case $L_{b}=1 \mathrm{~m}$, the failure load corresponds to crushing of the columns even for $e=50 \mathrm{~mm}$, while for $L_{b}=4.5 \mathrm{~m}$ buckling will be dominant. Therefore the coefficient of correction in POTFIRE procedure may have been better calibrated where buckling is dominant. It can be observed that for $L_{b}=4.5 \mathrm{~m}$ and $e=50 \mathrm{~mm}$, all results are almost identical for $R_{f}>30 \mathrm{~min}$.

\subsection{Influence of the percentage of steel rebars}

The following analyses show how the results given by the three methods are influenced by the percentage of steel reinforcement.

To this aim two types of cross sections already examined in this article have been considered (Table 7). In the designation of columns (e.g. S260x6.3-4Ø20), the letter (S) represents section shape (Square or Circular), the first number (260) denotes the width (for square) or diameter 
Table 6 Comparison between two methods for eccentrical loads for circular section 323.9x4 with $8 \varnothing 16-L_{b}=4.5 \mathrm{~m}$ without geometrical imperfection

\begin{tabular}{|c|c|c|c|c|c|c|c|c|c|c|c|c|c|c|c|c|c|}
\hline \multicolumn{6}{|c|}{ SAFIR EN1994 } & \multicolumn{6}{|c|}{ POTFIRE V2.0 - EN1994 } & \multicolumn{6}{|c|}{ POTFIRE V1.2 - ENV1994 } \\
\hline \multicolumn{6}{|c|}{ Eccentricity } & \multicolumn{6}{|c|}{ Eccentricity } & \multicolumn{6}{|c|}{ Eccentricity } \\
\hline \multicolumn{2}{|c|}{$10 \mathrm{~mm}$} & \multicolumn{2}{|c|}{$20 \mathrm{~mm}$} & \multicolumn{2}{|c|}{$50 \mathrm{~mm}$} & \multicolumn{2}{|c|}{$10 \mathrm{~mm}$} & \multicolumn{2}{|c|}{$20 \mathrm{~mm}$} & \multicolumn{2}{|c|}{$50 \mathrm{~mm}$} & \multicolumn{2}{|c|}{$10 \mathrm{~mm}$} & \multicolumn{2}{|c|}{$20 \mathrm{~mm}$} & \multicolumn{2}{|c|}{$50 \mathrm{~mm}$} \\
\hline $\begin{array}{l}\text { Load } \\
(\mathrm{kN})\end{array}$ & $\begin{array}{c}\mathrm{Rf} \\
(\mathrm{min})\end{array}$ & $\begin{array}{l}\text { Load } \\
(\mathrm{kN})\end{array}$ & $\begin{array}{c}\mathrm{Rf} \\
(\mathrm{min})\end{array}$ & $\begin{array}{l}\text { Load } \\
(\mathrm{kN})\end{array}$ & $\begin{array}{c}\mathrm{Rf} \\
(\mathrm{min})\end{array}$ & $\begin{array}{l}\text { Load } \\
(\mathrm{kN})\end{array}$ & $\begin{array}{c}\mathrm{Rf} \\
(\mathrm{min})\end{array}$ & $\begin{array}{l}\text { Load } \\
(\mathrm{kN})\end{array}$ & $\begin{array}{c}\mathrm{Rf} \\
(\mathrm{min})\end{array}$ & $\begin{array}{l}\text { Load } \\
(\mathrm{kN})\end{array}$ & $\begin{array}{c}\mathrm{Rf} \\
(\mathrm{min})\end{array}$ & $\begin{array}{l}\text { Load } \\
(\mathrm{kN})\end{array}$ & $\begin{array}{c}\mathrm{Rf} \\
(\mathrm{min})\end{array}$ & $\begin{array}{l}\text { Load } \\
(\mathrm{kN})\end{array}$ & $\begin{array}{c}\mathrm{Rf} \\
(\mathrm{min})\end{array}$ & $\begin{array}{l}\text { Load } \\
(\mathrm{kN})\end{array}$ & $\begin{array}{c}\mathrm{Rf} \\
(\mathrm{min})\end{array}$ \\
\hline 50 & 326 & 50 & 314 & 50 & 290 & 50 & 325 & 50 & 308 & 50 & 263 & 50 & 293 & 50 & 270 & 50 & 237 \\
\hline 100 & 234 & 100 & 212 & 100 & 171 & 100 & 213 & 100 & 199 & 100 & 172 & 100 & 197 & 100 & 183 & 100 & 162 \\
\hline 200 & 149 & 200 & 144 & 200 & 132 & 200 & 158 & 200 & 152 & 200 & 138 & 200 & 143 & 200 & 136 & 200 & 119 \\
\hline 300 & 123 & 300 & 117 & 300 & 105 & 300 & 137 & 300 & 129 & 300 & 114 & 300 & 117 & 300 & 109 & 300 & 100 \\
\hline 400 & 103 & 400 & 96 & 400 & 85 & 400 & 119 & 400 & 111 & 400 & 93 & 400 & 103 & 400 & 99 & 400 & 89 \\
\hline 500 & 87 & 500 & 81 & 500 & 70 & 500 & 104 & 500 & 95 & 500 & 77 & 500 & 95 & 500 & 90 & 500 & 78 \\
\hline 600 & 75 & 600 & 69 & 600 & 58 & 600 & 91 & 600 & 82 & 600 & 63 & 600 & 87 & 600 & 82 & 600 & 69 \\
\hline 800 & 57 & 800 & 52 & 800 & 40 & 800 & 70 & 800 & 61 & 800 & 43 & 800 & 73 & 800 & 67 & 800 & 39 \\
\hline 1000 & 45 & 1000 & 39 & 1000 & 28 & 1000 & 54 & 1000 & 45 & 1000 & 29 & 1000 & 57 & 1000 & 42 & 1000 & 23 \\
\hline 1200 & 37 & 1200 & 31 & 1200 & 21 & 1200 & 41 & 1200 & 34 & 1200 & 20 & 1200 & 36 & 1200 & 26 & 1200 & 15 \\
\hline 1400 & 30 & 1400 & 26 & 1400 & 15 & 1400 & 32 & 1400 & 25 & 1400 & 13 & 1400 & 25 & 1400 & 19 & 1400 & 5 \\
\hline 1600 & 25 & 1600 & 21 & 1600 & 10 & 1600 & 24 & 1600 & 19 & 1500 & 8 & 1600 & 19 & 1600 & 13 & 1410 & 4 \\
\hline 1800 & 21 & 1800 & 17 & 1800 & 6 & 1800 & 19 & 1800 & 13 & 1550 & 4 & 1800 & 13 & 1800 & 5 & 1420 & 2 \\
\hline 2000 & 18 & 2000 & 14 & 2000 & 4 & 2000 & 14 & 2000 & 4 & 1580 & 2 & 2000 & 7 & 1830 & 2 & 1425 & 1 \\
\hline 2200 & 14 & 2200 & 8 & 2200 & 2 & 2200 & 7 & 2040 & 2 & 1587 & 1 & 2010 & 6 & 1840 & 1 & 1430 & 0 \\
\hline 2400 & 10 & 2400 & 4 & 2250 & 1 & 2300 & 2 & 2045 & 1 & 1589 & 0 & 2030 & 5 & 1842 & 0 & - & - \\
\hline 2600 & 4 & 2600 & 2 & 2260 & 1 & 2310 & 1 & 2047 & 0 & - & - & 2040 & 4 & - & - & - & - \\
\hline 2800 & 1 & 2650 & 1 & 2270 & 0 & 2312 & 0 & - & - & - & - & 2060 & 3 & - & - & - & - \\
\hline 2850 & 1 & 2700 & 0 & - & - & - & - & - & - & - & - & 2070 & 2 & - & - & - & - \\
\hline 2875 & 1 & 2706 & 0 & - & - & - & - & - & - & - & - & 2080 & 1 & - & - & - & - \\
\hline 2888 & 0 & - & - & - & - & - & - & - & - & - & - & 2090 & 0 & - & - & - & - \\
\hline
\end{tabular}

(for circular) of the steel hollow section SHS, the second number (6.3) denotes the thickness of the tube and in the last term (4Ø20), numbers 4 and 20 respectively denotes the number and the diameter of the rebars.

Various amounts of the steel reinforcement have been chosen. All these columns are assumed to be hinged at both ends and have a total length of $3.5 \mathrm{~m}$; therefore $L_{b}=L_{t}=3.5 \mathrm{~m}$. The applied load is $1500 \mathrm{kN}$ for all cases. This load is slightly smaller than the maximum allowable one in Kodur's method. Since the square section has a larger slenderness ratio, a low value of fire resistance duration should be expected.

From Table 7, concerning the influence of the percentage of steel rebars, the fire resistance duration obtained by the method of KODUR are higher than those calculated by the two other methods. Also, it is surprising that this method gives the same fire resistance duration for the same section, with different percentage of steel reinforcement. The other two methods SAFIR EN1994 and POTFIRE V2.0 give similar results and the fire resistance durations increase with the increase of the reinforcement ratio in the columns section. In the author's opinion, the results obtained by these two methods are logical.

They remain the same within certain ranges of the percentage of reinforcement $\rho$. However, the other methods indicate that reinforcing percentage has a significant effect (square 260: Kodur no variation, SAFIR close to $10 \%$, POTFIRE close to $20 \%$; circular $323.9 \rho>3 \%$ : Kodur no variation, SAFIR $>10 \%$, POTFIRE $\approx 20 \%$ ).

As noted previously, Kodur's formulas give higher values than those given by the two other methods. They can be closer to the experimental results, but they can also be unsafe when applied to columns hinged at both ends, for the reason already mentioned.

\subsection{Comparison between two methods in the case of very small eccentricities}

This comparison aims at showing a discrepancy that can be observed in the results given by POTFIRE for very small eccentricities. 


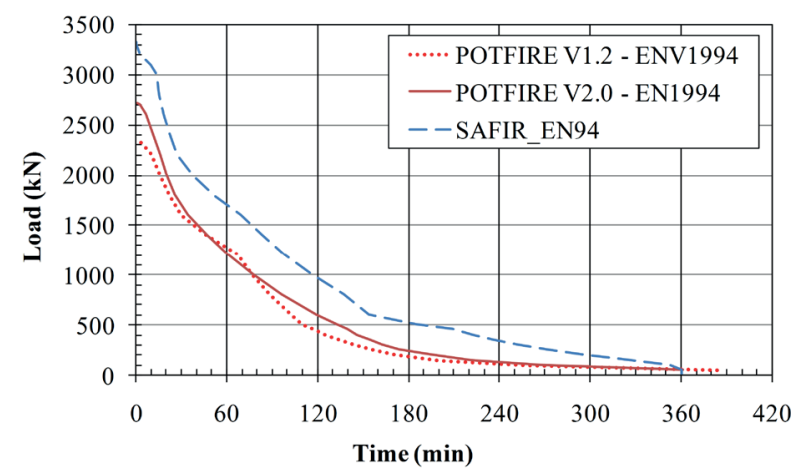

(a)

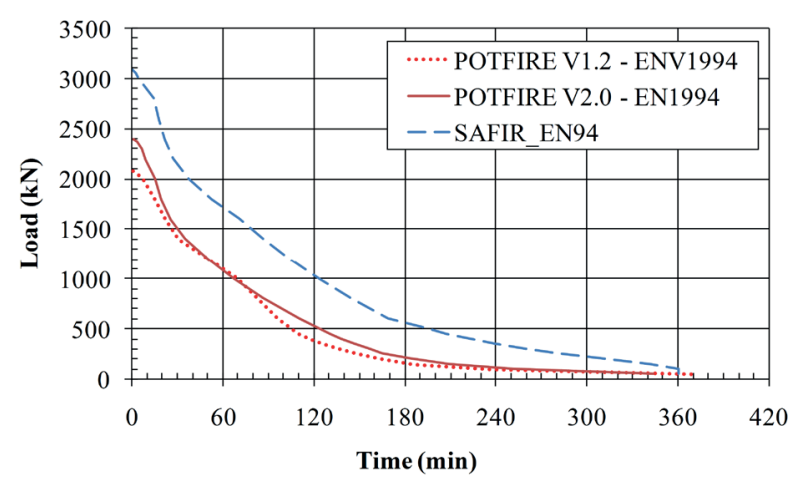

(b)

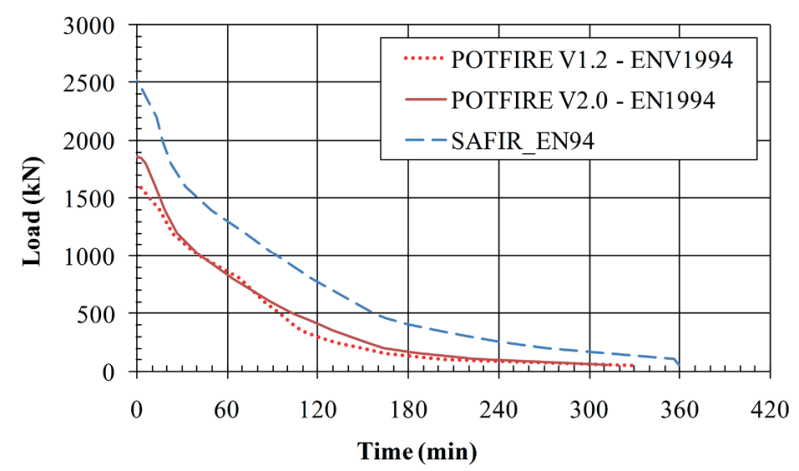

(c)

Fig. 8 Comparison between two methods for the case circular section $323.9 \times 4$ with $8 \varnothing 16$ and $\mathrm{Lb}=1 \mathrm{~m}$ for all values of $R_{f}$ : (a) eccentricity load $e=10 \mathrm{~mm}$, (b) eccentricity load $e=20 \mathrm{~mm}$ and (c) eccentricity load $e=50 \mathrm{~mm}$

For this analysis the circular column $323.9 \times 4$ with $8 \varnothing 16$ has been chosen. The column is assumed to be hinged at both ends with a total length $L_{t}=L_{b}=3 \mathrm{~m}$, corresponding to a mean value of the slenderness ratio. The eccentricity varies from 0 to $5 \mathrm{~mm}$ and thus very small values are considered.

Regarding the influence of the eccentricity of the axial compression load applied to the column, Table 8 summarizes the results of these loads for the two methods SAFIR EN 1994 and POTFIRE V2.0 and for the four classical values of the duration of fire resistance R30, R60, R90 and R120 minutes.

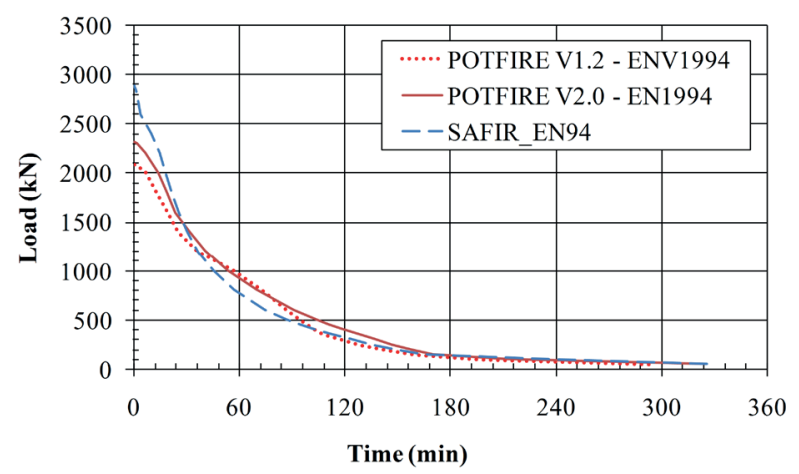

(a)

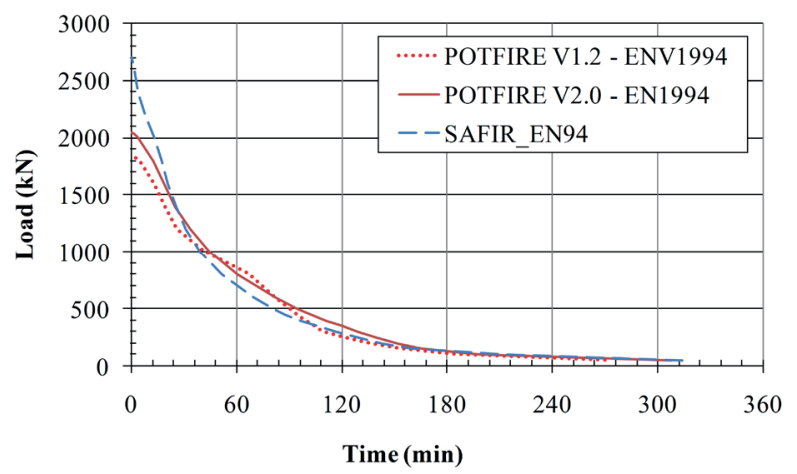

(b)

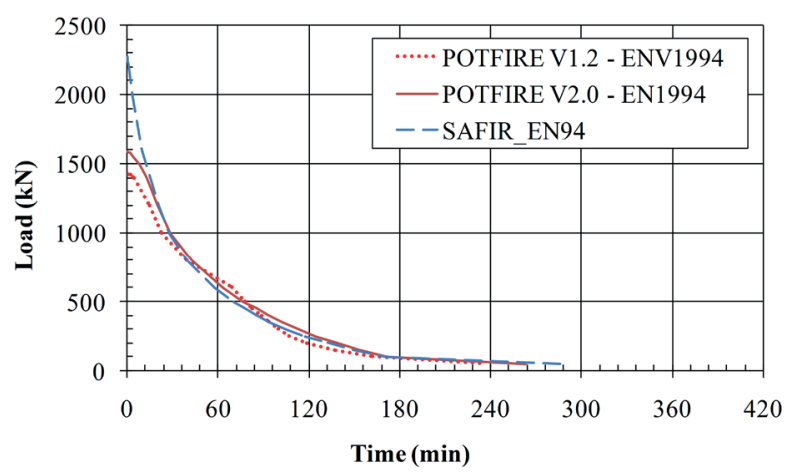

(c)

Fig. 9 Comparison between two methods for the case circular section $323.9 \times 4$ with $8 \varnothing 16$ and $\mathrm{Lb}=4.5 \mathrm{~m}$ for all values of $R_{f}$ : (a) eccentricity load $e=10 \mathrm{~mm}$, (b) eccentricity load $e=20 \mathrm{~mm}$ and (c) eccentricity

$$
\text { load } e=50 \mathrm{~mm}
$$

As a first remark, it is surprising to note that, for a very low eccentricity $(0.1 \mathrm{~mm})$, the axial compression loads calculated by POTFIRE decrease very rapidly (15\% of loss) with respect to the centered axial loads (eccentricity $=0$ ) and this for the four durations of fire resistance.

This finding is not observed for the SAFIR method which gives, for very small eccentricities $(0,0.1$ and $0.5 \mathrm{~mm})$, a low rate of reduction of compressive loads (1 to $2 \%$ ) compared to the centered axial compression loads. To better appreciate the difference between the two methods, it was considered useful to graph the Table 8 results for two types of fire resistance R60 and R120. 
Table 7 Influence of the percentage of reinforcement in the three methods

\begin{tabular}{|c|c|c|c|c|c|c|}
\hline \multirow[b]{2}{*}{ Section type } & \multirow[b]{2}{*}{$\begin{array}{c}\text { Percentage of } \\
\text { reinforcement } \\
\rho(\%)\end{array}$} & \multirow[b]{2}{*}{$\begin{array}{l}\text { Length of the } \\
\text { column } \\
\operatorname{Lt}(\mathrm{m})\end{array}$} & \multirow[b]{2}{*}{$\begin{array}{l}\text { Applied axial load } \\
\qquad \mathrm{C}(\mathrm{kN})\end{array}$} & \multicolumn{3}{|c|}{ Fire resistance (min) } \\
\hline & & & & $\begin{array}{l}\text { SAFIR EN1994 } \\
\text { Geometric } \\
\text { Imperfection } \\
\text { Lt / } 1000\end{array}$ & $\begin{array}{c}\text { POTFIRE V2.0 } \\
\text { EN1994 }\end{array}$ & KODUR \\
\hline S260x6.3-4Ø14 & 1 & 3.5 & 1500 & 29 & 32 & 43 \\
\hline S260x6.3-4Ø20 & 2.1 & & & 32 & 39 & 43 \\
\hline С323.9x4-8Ø14 & 1.6 & 3.5 & 1500 & 58 & 53 & 88 \\
\hline C323.9x4-8Ø16 & 2.1 & & & 68 & 62 & 88 \\
\hline C323.9x4-8Ø20 & 3.2 & & & 80 & 79 & 93 \\
\hline С $323.9 \times 4-8 Ø 25$ & 5.0 & & & 90 & 97 & 93 \\
\hline
\end{tabular}

Table 8 Influence of very small eccentricities in two methods for a circular section 323.9x4 with $8 \varnothing 16$ and $L_{t}=3 \mathrm{~m}$

\begin{tabular}{|c|c|c|c|c|c|c|c|c|}
\hline \multirow{3}{*}{$\begin{array}{l}\text { Eccentricity } \\
\mathrm{e}(\mathrm{mm})\end{array}$} & \multicolumn{8}{|c|}{ Axial load $(\mathrm{kN})$} \\
\hline & \multicolumn{4}{|c|}{ SAFIR-EN1994 without geometrical imperfection } & \multicolumn{4}{|c|}{ PotFire V2.0 EN1994 } \\
\hline & R30' & R60' & R90' & R120' & $30^{\prime}$ & R60' & R90' & R120' \\
\hline 0 & 2215 & 1535 & 1033 & 660 & 2084 & 1525 & 1080 & 724 \\
\hline 0.1 & 2186 & 1518 & 1019 & 647 & 1772 & 1297 & 918 & 616 \\
\hline 0.5 & 2140 & 1485 & 988 & 623 & 1761 & 1289 & 913 & 612 \\
\hline 1 & 2113 & 1459 & 963 & 610 & 1748 & 1280 & 906 & 607 \\
\hline 5 & 2015 & 1347 & 877 & 572 & 1649 & 1207 & 855 & 573 \\
\hline 10 & 1921 & 1269 & 833 & 547 & 1540 & 1127 & 798 & 535 \\
\hline 20 & 1761 & 1161 & 771 & 510 & 1363 & 998 & 706 & 474 \\
\hline 50 & 1401 & 945 & 638 & 421 & 1058 & 775 & 548 & 368 \\
\hline
\end{tabular}

Two particular cases $\left(R_{f}=60\right.$ and $\left.120 \mathrm{~min}\right)$ are examined in Figs. 10 and 11. The maximum admissible load has been calculated for the 4 classical values of the fire resistance duration time $\left(R_{f}=30\right.$ to $\left.120 \mathrm{~min}\right)$.

SAFIR is a numerical model which simulates the structural behavior and there is a continuous decrease of the admissible load. On the contrary, the values given by POTFIRE, show a relatively important drop when the eccentricity varies from 0 to very small values.

This is due to the manner that POTFIRE determines the fire resistance when the load is applied eccentrically (Eq. 7). For $e=0$, the admissible load is given by $N_{f i, R d}$ and for $\mathrm{e} \neq 0$, Eq.(7) is used. For a very small value of the eccentricity, the jump can be explained by the variation of the two parameters $\varphi_{S}$ and $\varphi_{\delta}[11]$. This sensitivity should be recognized within the POTFIRE Manual.

The results of Table 8 are presented in Figs. 10(a) and 11(a) show histograms for all selected eccentricities $(0,0.1 \ldots 50 \mathrm{~mm})$. In order to better see the initial drop, Figs. 10(b) and 11(b) show the same results when the eccentricity varies from 0 to $5 \mathrm{~mm}$ to better show the difference between the two methods and in particular for the two eccentricities 0 and $0.1 \mathrm{~mm}$.
As already noted, the load capacities predicted by SAFIR are higher than those given by POTFIRE in some cases, but in other cases they are very close to each other.

\section{Conclusions}

Concrete-filled tubular sections are commonly used in steel-framed construction and it is important to be able to determine the fire resistance of these members. This paper has provided a comparison of test results (which show considerable variability) for such members with the predictions of various methods of calculation - Kodur's empirical method, POTFIRE (three versions) and SAFIR, a finite element method.

The following conclusions are made with respect to each of the calculation methods:

Kodur's method (empirical formulas) is the most simple one. The values obtained are rather close to experimental results which is not so particularly surprising, as it was developed based on the laboratory fire tests. The fire resistance depends only on a limited member of parameters. It can provide the fire resistance duration of a given profile, or the maximum admissible load for a given fire resistance time. Therefore it is recommended to use this method for 


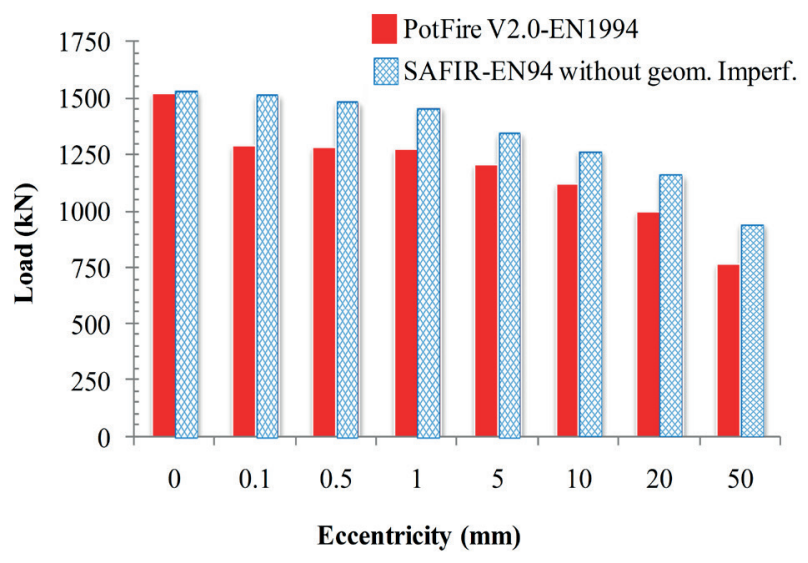

(a)

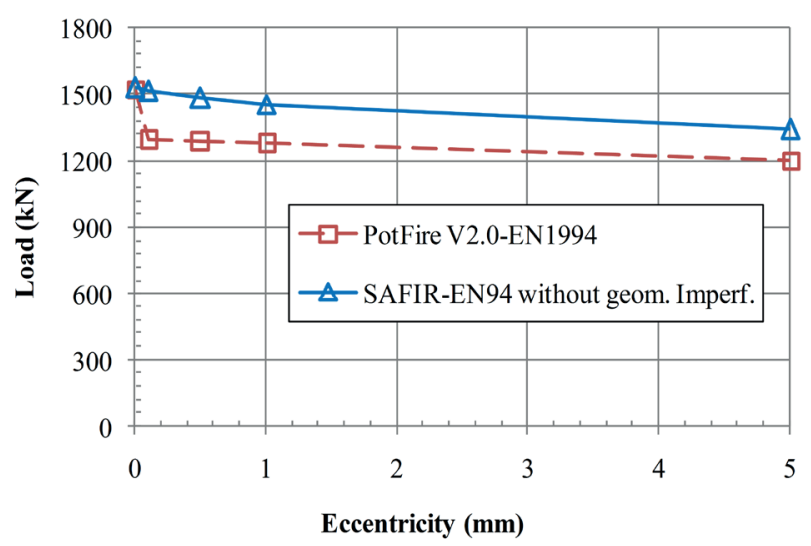

(b)

Fig. 10 Comparison SAFIR-POTFIRE for the case circular section $323.9 \times 4$ with $8 \varnothing 16$ and $L_{b}=3 \mathrm{~m}$ in fire duration $60 \mathrm{~min}$. (a) for all the values of the eccentricity; (b) for the eccentricity varying from 0 to $5 \mathrm{~mm}$

standard cases. The method has some limitations, most of them being explicit. It is applicable only for axial loads. It is valid only for standard fire conditions.

POTFIRE computer program is easy to apply. A user's manual is provided and clear instructions describe how to introduce the data. It can provide the fire resistance duration of a given profile, or the maximum load for a given fire resistance time. The method should be used for standard cases, though in most cases it gives results with wider safety margin. Therefore it could be recommended when Kodur's formulas do not apply. The method has some limitations. There is a discrepancy for low values of the eccentricity, and this should be noted in the User's Manual. It is valid only for standard fire conditions.

SAFIR is a non-linear computer code that can simulate the behavior of structures under various fire conditions. Therefore it can give a complete description of member behavior for varying temperature distribution and load conditions. The program is readily used by an experienced

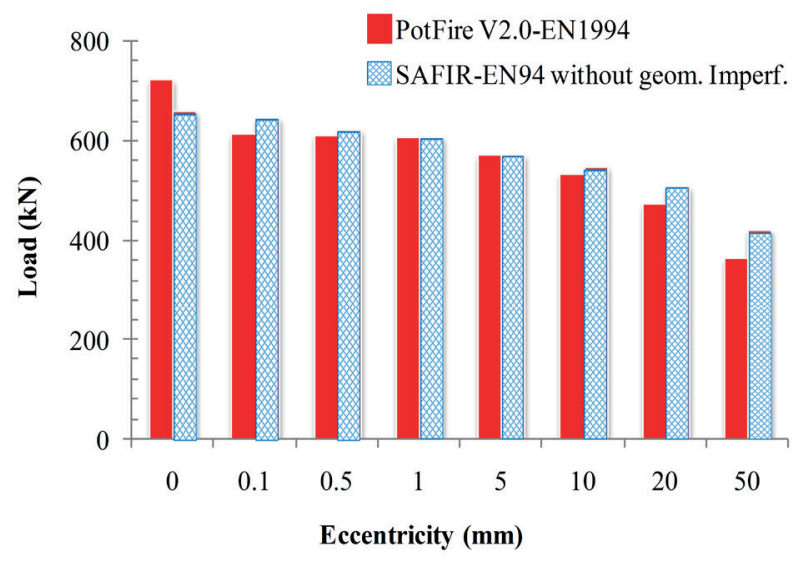

(a)

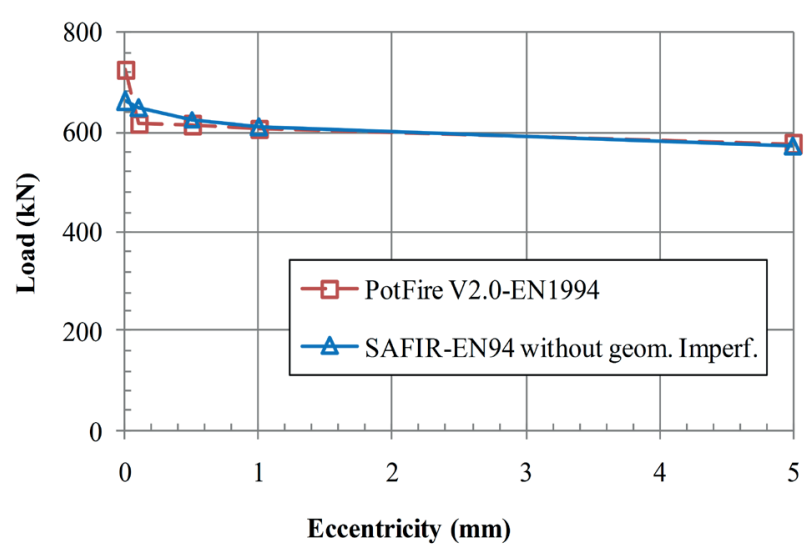

(b)

Fig. 11 Comparison SAFIR-POTFIRE for the case circular section $323.9 \times 4$ with $8 \varnothing 16$ and $L_{b}=3 \mathrm{~m}$ in fire duration $120 \mathrm{~min}$. (a) for all the values of the eccentricity; (b) for the eccentricity varying from 0 to $5 \mathrm{~mm}$

practitioner. Therefore this code should be recommended for sophisticated cases, e.g. a column in a frame submitted to a natural fire, this allowing performance-based structural fire design.

The only limitation is the following: SAFIR provides the fire resistance duration. To get the maximum admissible load for a given fire resistance time, it is necessary to perform several simulations at various load levels.

From this study, one may ask the following question: Why some predictions are inaccurate? In the author opinion, the differences in the results between considered calculation models "POTFIRE, Kodur and SAFIR" and experimental tests, are due to the fact that these methods do not take into account some very important factors in the calculation of the fire resistance, such as for example: the moisture migration, the concrete cracking, the local buckling of the steel tube, the transient creep and load-induced thermal strains in concrete and the formation of an air gap at the interface between the concrete core and the steel tube. 
Also, it is difficult to model the buckling length compared to reality during testing. Furthermore, the parameters of slenderness and modes of support are very important in the estimation of the failure load at elevated temperatures. Indeed, as it was observed during the experimental tests carried out on columns of concrete-filled steel tube, ruin can occur either by global buckling for slender columns or by local buckling of the steel tube and/ or crushing of the concrete core, for short columns [22]. Moreover, it is difficult to know the real supporting conditions during testing. The majority of tests $(\approx 64 \%)$ have been performed on the nominally fixed-fixed members, although it is worth noting that the true fixity during testing is never perfect and is usually not known [22].

The author recommends the SAFIR calculation code which is the most universal method, guaranteeing safe and

\section{References}

[1] Guiaux, P., Janss, J. "Comportement au flambement de colonnes constituées de tubes en acier remplis de béton" (Buckling behaviour of steel hollow section columns filled with concrete), Research report, CRIF, Centre de Recherches Scientifiques et Techniques de l'Industrie des Fabrications Métalliques, Brussels, Belgium, Rep. MT65, 1970. (in French)

[2] Stochino, F., Mistretta, F., Meloni, P., Carcangiu, G. "Integrated Approach for Post-fire Reinforced Concrete Structures Assessment", Periodica Polytechnica Civil Engineering, 61(4), pp. 677-699, 2017. https://doi.org/10.3311/PPci.9830

[3] Grandjean, G. "Etude de la tenue au feu des profils creux carrés remplis de béton" (Study of the fire resistance of square steel hollow section filled with concrete), Graduation Project, Ecole Nationale des Ponts et Chaussées, Paris, France, 1975. (in French)

[4] Grimault, J. P., Mouty, J. "Prévision de la stabilité au feu des poteaux en profils creux remplis de béton" (Predicting the fire resistance of columns in concrete filled hollow sections), Construction Métallique, 3, pp. 45-57, 1984. (in French) [online] Available at: http://pascal-francis.inist.fr/vibad/index.php?action=getRecordDetail\&idt=8917171 [Accessed: 17 December 2019]

[5] European Commission for Constructional Steelwork (ECCS) "Calculation of the fire resistance of centrally loaded composite steel-concrete columns exposed to the standard fire. Technical Note", ECCS Technical Secretariat, 55, Brussels, Belgium. 1988. [online] Available at: https://books.google.dz/books/about/Calculation_of the_fire_resistance_of_ce.html?id=BsturgEACAAJ\&redir_esc $=\mathrm{y}$ [Accessed: 17 December 2019]

[6] Lie, T. T., Chabot, M. "Experimental Studies on the Fire Resistance of Hollow Steel Columns Filled with Plain Concrete", National Research Council of Canada, Ottawa, Canada, Rep. 611, 1992. http://doi.org/10.4224/20358480

[7] Chabot, M., Lie, T. T. "Experimental Studies on the Fire Resistance of Hollow Steel Columns Filled with Bar-Reinforced Concrete", National Research Council of Canada, Ottawa, Canada, Rep. 628, 1992. http://doi.org/10.4224/20358523 credible estimates in most cases. It is based on advanced calculation model which can be used for individual structural members, subassemblies or entire structures.

Compared to the simplified calculation models and tabulated data methods of Eurocode 4 EN 1994-1-2 [11], the advanced calculation models give better approximation to the real structural behavior in fire situation. In structural SAFIR's code analysis, several modeling factors can be used with no limitations or restrictions, such as time-temperature heating curves, temperature dependent mechanical and thermal properties of the materials, combined effects of mechanical actions, geometrical imperfections, thermal actions, geometrical non-linear effects, effects of non-linear material properties, support conditions and etc.

[8] Kodur, V. K. R., Lie, T. T. "Experimental Studies on the Fire Resistance of Circular Hollow Steel Columns Filled with SteelFibre-Reinforced Concrete", National Research Council of Canada, Ottawa, Canada, Rep. 691, 1995. http://doi.org/10.4224/20375221

[9] European Committee for Standardization "EN 1994-1-1:2004 Eurocode 4: Design of Composite Steel and Concrete Structures. Part 1-1: General Rules and Rules for Buildings", CEN, Brussels, Belgium, 2004. [online] Available at: https://www.phd.eng.br/ wp-content/uploads/2015/12/en.1994.1.1.2004.pdf [Accessed: 17 December 2019]

[10] European Committee for Standardization "ENV 1994-1-2:1994 Eurocode 4: Design of Composite Steel and Concrete Structures. Part 1-2: General Rules - Structural Fire Design", CEN, Brussels, Belgium, 1994. [online] Available at: https://infostore.saiglobal. com/en-gb/Standards/ENV-1994-1-2-94-AC-95-331242_SAIG_ CEN_CEN_761796/[Accessed: 17 December 2019]

[11] European Committee for Standardization "EN 1994-1-2:2005 Eurocode 4: Design of Composite Steel and Concrete Structures. Part 1-2: General Rules - Structural Fire Design", CEN, Brussels, Belgium, 2005. [online] Available at: https://www.phd.eng.br/ wp-content/uploads/2015/12/en.1994.1.2.2005.pdf [Accessed: 17 December 2019]

[12] Lie, T. T., Kodur, V. K. R. "Fire Resistance of Steel Columns Filled with Bar-Reinforced Concrete", ASCE Journal of Structural Engineering, 122(1), pp. 30-36, 1996. https://doi.org/10.1061/(ASCE)0733-9445(1996)122:1(30)

[13] Kodur, V. K. R., Mackinnon, D. H. "Design of concrete filled hollow structural steel columns for fire endurance", Engineering Journal, 37(1), pp. 13-24, 2000. [online] Available at: https://nparc.nrc-cnrc. gc.ca/fra/voir/accept $\%$ C3\%A9/?id=54202118-72dc-4ffb-bbdc-cfd74cce5e74 [Accessed: 17 December 2019] 
[14] CTICM "Logiciel POTFIRE - Evaluation de la stabilité au feu" (POTFIRE. Software to evaluate the fire stability of unprotected concrete filled hollow sections columns), 2009. [computer program] Available at: https://www.cticm.com/content/potfire-logiciel-stabilite-feu-poteaux-dtu-eurocode-4 [Accessed: 17 December 2019]

[15] Franssen, J. M. "SAFIR. A thermal/structural program modelling structures under fire", Engineering Journal, 42(3), pp. 143-158, 2005. [online] Available at: http://hdl.handle.net/2268/2928 [Accessed: 17 December 2019]

[16] Chu, T. B., Gernay, T., Dotreppe, J. C., Franssen, J. M. "Steel hollow columns with an internal profile filled with self-compacting concrete under fire conditions", In: Proceeding of the Romanian Academy. Series A, Mathematics, Physics, Technical Sciences, Information Science, 17(2), 2016, pp. 152-159. [online] Available at: https:// orbi.uliege.be/handle/2268/181444 [Accessed: 17 December 2019]

[17] Binh, C. T., Dotreppe, J. C., Franssen, J. M. "Numerical modelling of building structures in fire conditions", In: Proceedings of the workshop on "Construction under Exceptional Condition. CEC2010", Hanoi, Vietnam, 2010, pp. 41-52. [online] Available at: http://hdl. handle.net/2268/78436 [Accessed: 17 December 2019]

[18] American Society for Testing and Materials "ASTM E119-00a: Standard Methods of Fire Tests on Building Construction and Materials", ASTM, West Conshohockan, PA, USA, 1988. [online] Available at: https://www.technokontrol.com/pdf/walls_astm.e119. 2000.pdf [Accessed: 17 December 2019]

[19] Danish Standard "DS ISO 834 - 10: 2014: Fire resistance tests Elements of building constructions", Danish Standards, Copenhagen, Denmark, 2014. [online] Available at: https://infostore.saiglobal. com/en-gb/Standards/DS-ISO-834-10-2014-484844_SAIG_DS_ DS_1086530/[Accessed: 17 December 2019]
[20] Renaud, C. "Modélisation numérique, expérimentation et dimensionnement pratique des poteaux mixtes avec profil creux exposés à l'incendie" (Numerical modeling, experimentation and practical dimensioning of composite steel hollow section columns exposed to fire), $\mathrm{PhD}$ thesis INSA de Rennes, 2003. (in French)

[21] Kwasniewski, L., Krol, P. A., Lacki K. "Virtual Tests on Axially and Rotationally Restrained Steel Column Under Fire", Journal of Structural Fire Engineering, 2(2), pp. 109-121, 2011. https://doi.org/10.1260/2040-2317.2.2.109

[22] Rush, D., Bisby, L., Jowsey, A., Melandinos, A., Lane, B. "Structural performance of unprotected concrete-filled steel hollow sections in fire: A review and meta-analysis of available test data", Steel and Composite Structures, 12(4), pp. 325-352, 2012.

https://doi.org/10.12989/scs.2012.12.4.325

[23] European Committee for Standardization "EN 1993-1-1:2004 Eurocode 3: Design of Steel Structures. Part 1-1: General Rules and Rules for Buildings", CEN, Brussels, Belgium, 2004. [online] Available at: https://www.phd.eng.br/wp-content/uploads/2015/12/ en.1993.1.1.2005.pdf [Accessed: 17 December 2019]

[25] Kwasniewski, L., Krol, P., Lacki, K. "Numerical modeling of steel columns in fire", In: Mazzolani, F. M. (ed.) COST Action C26 Urban Habitat Constructions under Catastrophic Events. Proceedings of the Final Conference, Naples, Italy, pp. 237-242, 2010. [online] Available at: https://books.google.fr/books?id=Q9XKBQAAQBAJ\&printsec $=$ frontcover\&hl $=$ fr\&source $=$ gbs_ge_summary_r\&$\mathrm{cad}=0 \# \mathrm{v}=$ onepage $\& \mathrm{q} \& \mathrm{f}=$ false [Accessed: 17 December 2019] 